\title{
Revisión del género Gaultheria L. (Ericaceae) en Chile
}

\section{Revision of the genus of Gaultheria L. (Ericaceae) in Chile}

\author{
Sebastián Teillier* \& Felipe Escobar \\ Escuela de Arquitectura del Paisaje, Universidad Central, Santa Isabel 1160, Santiago, Chile. \\ *steillier@gmail.com
}

\begin{abstract}
RESUMEN
Se realizó una revisión del género Gaultheria L. (Ericaceae) presente en Chile, utilizando los métodos clásicos. Se tuvieron a la vista los tipos y las colecciones de los herbarios SGO y CONC, además de los sitios WEB de instituciones que contienen fotos de tipos o isotipos. Se concluyó que Gaultheria es un género que en Chile presenta varias complejidades: una centena de nombres propuestos por los científicos botánicos de todos los tiempos, taxa complejos con amplísima variación en la morfología foliar como G. mucronata, G. poeppigii y G. racemulosa, taxa intermedios entre especies (posibles híbridos) y taxa indistinguibles en ausencia de frutos ( $G$. phyllireifolia-G. mucronata). Como conclusión de la revisión se aceptan para Chile 12 especies y una variedad: G. angustifolia, G. antarctica, G. cespitosa, G. insana, G. mucronata, G. nubigena, G. phyllireifolia, G. poeppigii, G. pumila, G. pumila var. leucocarpa, G. racemulosa, G. renjifoana y G. tenuifolia. Se rehabilitan $G$. renjifoana, una especie amenazada de extinción incluida en forma errada en la sinonimia de $G$. insana; y $G$. angustifolia, una especie afín a $G$. mucronata, pero con hojas más estrechas y diferentes hábitat y distribución geográfica. Finalmente, se llama la atención sobre G. nubigena, una especie de distribución muy estrecha que merece protección.
\end{abstract}

Palabras clave: Gaultheria, Ericaceae, flora de Chile.

\begin{abstract}
A review of Gaultheria L. has been made through taxonomic methods. Specimens and documents from SGO and CONC herbariums, as well as different institution's web sites containing pictures of specimens, are reviewed in this document. It was concluded that Chile has several complexities regarding Gaultheria: hundreds of names have been proposed by botanists; species complexes with wide foliar variation, such as G. mucronata, G. poeppigii and G. racemulosa; intermediate taxa among species (putative hybrids) and indistinguishable taxa in the absence of fruits (G. phyllireifolia-G. mucronata). As a conclusion, we propose 12 species and one variety accepted in Chile: G. angustifolia, G. antarctica, G. cespitosa, G. insana, G. mucronata, G. nubigena, G. phyllireifolia, G. poeppigii, G. pumila, G. pumila var. leucocarpa, G. racemulosa, G. renjifoana and G. tenuifolia. G. renjifoana is being maintained, even though this endangered species had been considered as synonymous with $G$. insana. We reinstate G. angustifolia, a species which differs from G. mucronata on the basis of habitat and geographic distribution. Finally it is underlined that G. nubigena should be protected due to its narrow distribution.
\end{abstract}

KEYwords: Gaultheria, Ericaceae, flora of Chile.

\section{INTRODUCCIÓN}

Las Ericaceae nativas de Chile han sido revisadas a lo largo del tiempo por destacados botánicos tales como Reiche (1905), Kausel (1949), Sleumer $(1935,1985)$ y Sleumer \& Hermann (1999); de tal modo que se encuentran bastante bien conocidas, sin embargo, aún existen algunas dudas sobre la validez de algunos taxa al nivel de las especies y de las variedades.
En Chile, el género Gaultheria se distribuye entre la provincia de Los Andes (cajón del Colorado, río Aconcagua) y el extremo sur del país, con dos excepciones, que corresponden a extensas disyunciones: $G$. insana que crece en los oasis de neblina en las cercanías de Paposo (Región de Antofagasta) y G. angustifolia, que se encontró en el relicto de bosque valdiviano de Fray Jorge (Región de Coquimbo) (Muñoz Pizarro \& Pisano 1947, Squeo et al. 2001). Las Ericaceae forman parte del elenco de especies de 
los bosques valdivianos y andino-patagónicos del extremo sur de Sudamérica; sólo G. renjifoana es endémica de Chile continental (Muñoz-Schick 1987). G. racemulosa es endémica del archipiélago de Juan Fernández. G. pumila var. leucocarpa tiene una distribución de carácter netamente andino, y de acuerdo con Schmithüsen (1956), su presencia en la vegetación zonal andina de la cuenca del río Cachapoal correspondería al límite norte de los Andes mediterráneos húmedos.

Desde el punto de vista del hábito, las especies chilenas son arbustos, o subarbustos con tallos frecuentemente radicantes, como G. antarctica, G. caespitosa y G. pumila, hasta mayores como G. insana, G. phyllireifolia y $G$. prostrata, los que alcanzan hasta $250 \mathrm{~cm}$ de altura. La más diferente y desconocida de las especies es G. nubigena, que, al parecer, es un arbusto apoyante.

De acuerdo con Kausel (1949), las especies de Gaultheria en general son plantas heliófilas. Posiblemente, crecen en suelos ácidos y son micotróficas como lo son casi todos los representantes de la familia (Mabberley 1987, Stevens 2001). G. mucronata y G. phyllireifolia forman parte de los matorrales secundarios que suceden a la tala de los bosques templados (Luebert \& Pliscoff 2006). G. antarctica es común en los suelos turbosos y en las turberas propiamente tales; G. angustifolia crece en suelos muy inundados como los de los ñadis. G. poeppigii y G. pumila son especies de montaña.

Si bien no se conocen usos directos de las especies, el pueblo mapuche las conoce como "chauras" y se alimenta con sus frutos, los que en el caso de G. mucronata y $G$. poeppigii son grandes y sabrosos y se utilizan, además, para la fabricación de las chichas; existen, además, antecedentes que yámanas y selk-nam consumían los frutos de $G$. mucronata y G. pumila (Mösbach 1992, Pardo \& Pizarro 2005, Domínguez 2010).

Por la belleza de su floración y de su fructificación, $G$. insana y G. mucronata podrían utilizarse como arbustos ornamentales tal como proponen Riedemann \& Aldunate (2003), mismo uso que podrían tener G. poeppigii y $G$. angustifolia.

Uno de los principales problemas respecto del tratamiento de este grupo es la dificultad que existe para dilucidar si efectivamente Gaultheria y Pernettya constituyen un mismo género, tal como lo plantean Stevens (1971) y Middleton \& Wilcock (1990). No es objetivo de este trabajo resolver tal problema, sin embargo es importante establecer que en el material chileno no hay dudas respecto a que existen dos grupos de especies, con una discontinuidad muy clara, al nivel de la morfología: "Gaultheria" con fruto de tipo cápsula, rodeado por los sépalos acrescentes en la madurez, y "Pernettya", cuyo fruto es una baya verdadera. En el último tiempo se mantiene la tendencia de incluir a las especies en un mismo género, al respecto, ver los trabajos de Bush que utiliza herramientas moleculares (Bush et al.
2006, Bush \& Kron 2008, Bush et al. 2009). Las especies que forman bayas verdaderas $G$. insana, G. mucronata, $G$. poeppigii y $G$. pumila forman un grupo de afinidad; lo mismo que G. phyllireifolia, G. tenuifolia y G. nubigena; $G$. antarctica y $G$. caespitosa forman parte de un clado distinto (Bush et al. 2009).

Otro aspecto que ha complicado la clasificación del grupo en Chile es la amplia variabilidad que presentan algunas especies en la morfología de las hojas. Hojas aovadas hasta casi lineales se encuentran en G. racemulosa, especie endémica del archipiélago de Juan Fernández y $G$. poeppigii.

La presencia de individuos con caracteres intermediarios entre especies llamó ya la atención de Kausel (1949), quien ante las dificultades de determinar individuos cordilleranos de Gaultheria debió escribir en sus etiquetas que podían ser G. poeppigii x G. pumila (P. myrtilloides x P. pumila).

La amplia variación morfológica y la presencia de individuos sindicados como híbridos complicaron la taxonomía del grupo, llevando a los botánicos antiguos a describir numerosas especies. Existen casi 100 nombres diferentes propuestos para los trece taxa que crecen en nuestro país; existen, además, numerosos ejemplares-tipo que carecen de los frutos lo que genera mucha inseguridad respecto de su correcta atribución a las especies (ver: incertae sedis).

Finalmente, otro asunto que ha traído controversia ha sido el estatus de $G$. renjifoana como especie válida. Muñoz-Schick (1987) la rehabilitó considerando que tiene caracteres suficientes para mantenerla separada de otras especies como G. insana con la que ha sido confundida; este criterio no fue seguido por Middleton \& Wilcock (1990), ni por Zuloaga et al. (2008). En este trabajo se sigue el criterio de Muñoz-Schick y se llama la atención sobre la especie pues se trata de una planta fuertemente amenazada (ver tratamiento de la especie).

El objetivo de este trabajo, realizado en el marco de las investigaciones del proyecto Flora de Chile, es presentar una contribución al conocimiento de las especies de Gaultheria que crecen en el país, integrando datos de la variación de la morfología y de la distribución geográfica de las especies.

\section{METODOLOGÍA}

Se utiliza la metodología clásica de la taxonomía. Se revisó la bibliografía referente a la familia, particularmente las propuestas de Reiche (1905), Sleumer $(1935,1985)$, Kausel (1949) y Sleumer \& Hermann (1999). Se revisaron los tipos que existen en el herbario del Museo Nacional de Historia Natural (SGO) y algunas fotos disponibles en sitios de Internet $(\mathrm{K}, \mathrm{F})$. Además, se estudió todo el material de la familia que se encontró en los herbarios SGO y CONC. 


\section{RESULTADOS}

Como resultado de la revisión bibliográfica y de materiales de herbario se concluyó que en el país crecen doce especies y una variedad de Gaultheria sensu Middleton \& Wilcock (1990).

Clave para identificar las especies de GaUltheria en Chile

Nota: para una determinación segura se requiere de frutos maduros.

1. Fruto una cápsula envuelta en la madurez por un cáliz carnoso y acrescente

1 '. Fruto una baya; cáliz ni carnoso, ni acrescente.

2. Hojas con cilios muy evidentes en el borde.

2'. Hojas sin cilios en los bordes

3. Flores en inflorescencias multifloras. Hojas no mucronadas.

3'. Flores solitarias o en cimas 2-3-floras. Hojas mucronadas....

4. Hojas de $1-5 \mathrm{~cm}$ de longitud.

4'. Hojas de menos de $1 \mathrm{~cm}$ de longitud.

5. Hojas de 1-2 cm de longitud, aovadas hasta obovado-lanceoladas.

5'. Hojas mayores que $2 \mathrm{~cm}$ de longitud, lanceoladas.... fruto.

A continuación se presenta una clave y la descripción de ellas, incluyendo su distribución geográfica y algunos comentarios pertinentes relacionados con su validez.

6'.Hojas aovado-oblongas, margen con 4-6 dientes marcados. Flores pentámeras. Cáliz rojo a la madurez del

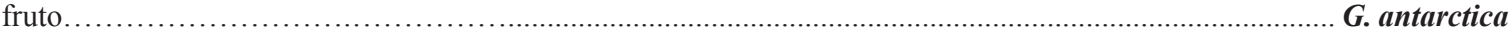

7. Flores dispuestas en cimas ramificadas, multifloras. Hojas de 5-9 $\mathrm{cm}$ de longitud. Corola de 6-7 mm de longitud.

G. insana

7'. Flores solitarias o en cimas 1-2 floras. Hojas menores que $5 \mathrm{~cm}$ de longitud. Corola de 3-4 mm de longitud....

8. Arbusto con ramas tendidas o erguidas de hasta $10 \mathrm{~cm}$ de altura. Hojas de $0,2-1 \mathrm{~cm}$ de longitud, margen entero o con 1-2 dientes en cada lado. Pedúnculo del fruto de 2-3 cm de longitud.

G. pumila

8'. Arbustos siempre erguidos, mayores que $10 \mathrm{~cm}$ de altura. Hojas con el margen aserrado o crenado, raro entero, con más de dos dientes a cada lado, a veces, con un mucrón apical poco pronunciado. Fruto con pedúnculo menor.......9

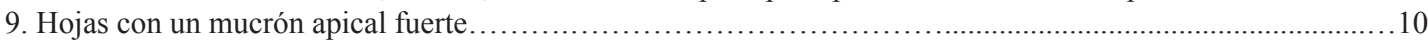
9'. Hojas sin mucrones, a veces, muy agudas.......

10. Hojas aovadas a aovado-oblongas, 4-10 mm ancho; mucrón siempre rígido. .................... mucronata

10'. Hojas lanceoladas a lineares, 1-3 mm de ancho; mucrón rígido a débil.

G. angustifolia

11. Hojas aovadas, aovado-elípticas hasta elípticas, 1,2-1,8 (2,5) cm de longitud; nervaduras prominentes en la haz (archipiélago Juan Fernández).....

G. racemulosa 11'. Hojas oblongas hasta elípticas, a veces angostadas, 1-2 cm; nervaduras no prominentes en la haz (en el continente)

G. poeppigii

DESCRIPCIÓN DE LAS ESPECIES

1. Gaultheria angustifolia (Lind1.) Teillier nov. comb. Basiónimo: Pernettya angustifolia Lindl., Edwards's Bot. Reg. 26: tab. 63.1840. Ex hortus: Lindley anno 1840, cult. Birmingham Botanical Garden (foto del tipo de Pernettya angustifolia en K).

Pernettya mucronata (L.f.) Gaudich. ex Spreng. var. angustifolia (Lindl.) Reiche, Anales Univ. Chile 117: 491. 1906; P. leucocarpa DC. var. linearis Reiche, pro parte. Anales Univ. Chile 117: 494. 1906. Gaultheria mucronata (L.f.) Hook. var. angustifolia (Lindl.) D.J. Middleton, Edinburgh. J. Bot. 47(3): 298. 1990.
CHAURA

Arbusto de 20-100 cm de altura, a veces con tallos radicantes. Hojas glabras, discolores, con las nervaduras principales fuertemente marcadas en el envés, cortamente pecioladas, lineares a lanceolado-elípticas u oblongas, de 12-15 (18) x ca. $3 \mathrm{~mm}$, borde aserrado, los dientes muy agudos hasta mucronulados; con un pequeño reborde, muy atenuadas en el ápice y en la base, de consistencia poco rígida y mucrón breve. Especie dioica. Flores unisexuales, solitarias, axilares, pedicelo de 4-8 mm. Cáliz 5-partido, lóbulos de $2 \mathrm{~mm}$ angostamente triangulares, algo agudos. Flores masculinas con una corola de $c a .5 \mathrm{~mm}$, campanulada; androceo con 10 estambres, anteras de $1 \mathrm{~mm}$, filamentos de 1,2-1,5 mm; gineceo con ovario de $1,2 \mathrm{~mm}$, piriforme, estéril. Flores 
femeninas con una corola de $c a .4 \mathrm{~mm}$, urceolado-cilíndrica; estambres estériles; gineceo con ovario fértil, estigma con 5 lóbulos bien desarrollados. Fruto, una baya de 6-8 (10) mm de diámetro, deprimida en la base y el ápice, casi globosa, rosada, cáliz ni acrescente ni carnoso (Fig. 1a).

DistribuCión GeOgRÁfica: Especie nativa de Chile y Argentina. En Chile tiene una distribución disyunta, encontrándose una población aislada y con carácter relicto en la localidad de Fray Jorge (Región de Coquimbo) y luego, desde la provincia de Arauco hasta la de Chiloé; es frecuente en sitios húmedos incluso en los suelos anegados de los ñadis y pantanos (Kausel 1949).
OBSERVACIÓn: En ausencia de frutos, se asemeja a $G$. tenuifolia, especialmente aquellos ejemplares con hojas lanceoladas y estrechas. En material con frutos, se distingue de su afín G. mucronata por las hojas estrechamente lanceoladas a lineares y por el mucrón muy corto en el ápice, a veces visible sólo con lupa; también se puede confundir con G. poeppigii, de la que se distingue por la presencia del mucrón terminal en las hojas, aunque ejemplares poco mucronados de esta especie y agudos de G. poeppigii, son de difícil asignación, en tal caso los frutos redondeados, algo deprimidos en la base y el ápice de G. angustifolia ayudan a distinguirla de los más oblongos y no deprimidos de G. poeppigii.
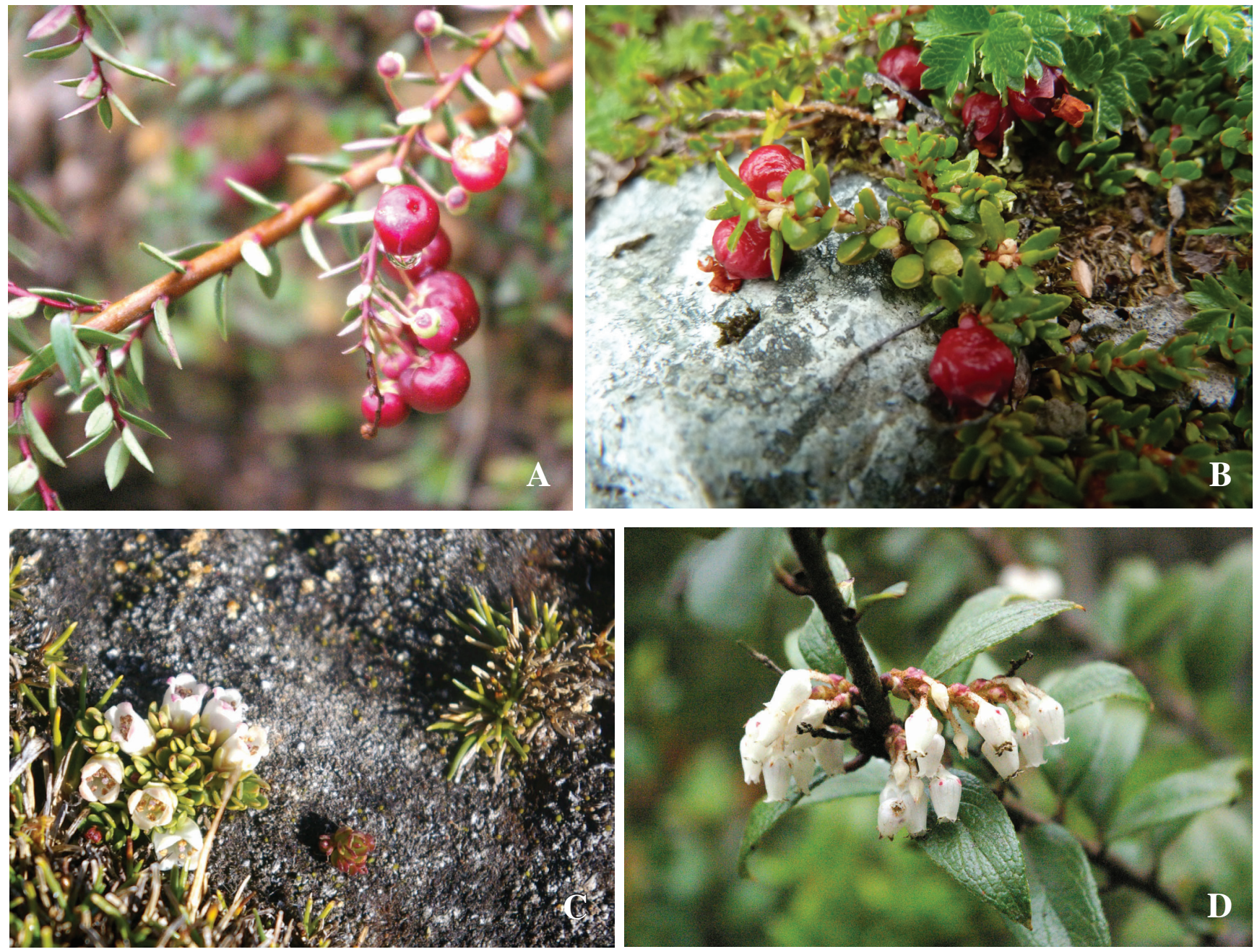

Figura 1. A. Gaultheria angustifolia (Lindl.) Teillier, rama con frutos. Cordillera de San Pedro, isla Grande de Chiloé (Fotografía del autor); B. Gaultheria antarctica Hook. f., rama con frutos. Reserva Biológica de Huilo Huilo, cerro Piedra del Encanto (Fotografía de Catherine Bonnemaison), C. Gaultheria caespitosa Poepp. et Endl., flores. Valle del río Colorado, provincia de Los Andes (Fotografía del autor), D. Gaultheria insana (Molina) D.J.Middleton, rama con flores. Reserva privada Namún Lahual-Puerto Montt (Fotografía del autor).

Figure 1. A. Gaultheria angustifolia (Lindl.) Teillier, branch with fruits. Cordillera de San Pedro, isla Grande de Chiloé (Photo by the author); B. Gaultheria antarctica Hook. F., branch with fruits. Huilo Huilo, Biological Reserve mountains of Piedra del Encanto (Photo: Catherine Bonnemaison), C. Gaultheria caespitosa Poepp. et Endl., flowers. Colorado valley, provincia de Los Andes (Photo by the author), D. Gaultheria insana (Molina) D.J.Middleton, flowering branch. Namún Lahual Reserve-Puerto Montt (Photo by the author). 
Los ejemplares provenientes de la cordillera de San Pedro (Chiloé) son muy particulares en su morfología, caracterizándose por hojas casi lineares y mucronadas.

El ejemplar tipo de Pernettya leucocarpa DC. var. linearis Reiche, contiene dos ejemplares; uno corresponde al tipo; el otro, que proviene del "Ñadi de Puyehue", a $G$. angustifolia.

Aceptada por Kausel (1949) bajo Pernettya angustifolia Lind.

Materiales estudiados: Región de Coquimbo: Prov. de Limarí, P.N. Fray Jorge, 550 m, 21-XI-2000, G. Arancio 14578 (ULS). Región del Bío Bío: Prov. de Arauco, Lebu, cerros, 65 m, 31-X-1964, G. Montero 6924 (CONC); entre Tirúa y Quidico, Llibilao, 140 m, 06-I-1977, C. Marticorena, M. Quezada \& R. Rodríguez, 1163 (CONC). Región de la Araucanía: Prov. de Cautín, Afquintue, 08XI-1962, G. Montero (CONC); Quepe, línea férrea hacia Freire, 90 m, 28-XII-1966, G. Montero 7814 (CONC). Región de Los Ríos: Prov. de Valdivia, San Juan, Valdivia. I/1880, F. Philippi (SGO); Huiti, Los Ñadis, 14-I-1957, A. Pfister s/n. (CONC, 19527). Región de Los Lagos: Prov. de Osorno, Puyehue, ñadi, 04- III-1965, C. Ramírez (CONC). Prov. Llanquihue, Maullín, fundo Las Chilcas, 29-I-1952, Klenner s/n. (CONC); Petrohué, 210 m, 27-I-1972, R. Rodríguez 03 (CONC); Chin Chin, NW de Puerto Montt, 150 m, 19-II-1972, E. Pisano \& Geni 1268 (CONC); entre Puerto Montt y Puerto Varas, 50 m, 5-III-1982, L. Landrum, 4354 (SGO). Prov. de Chiloé, Trumao, cerca de Los Molinos del Río Grande, Chiloé, 01-VI-1932, Junge s/n. (CONC); Piruquina, Isla de Chiloé, 08-III-1935, Junge s/n. (CONC); Cordillera de San Pedro, 200 pies, 18-XI-1958, Godley 500a (SGO); Cordillera San Pedro-Piruquina, Isla de Chiloé, 26-X-1970, Martínez s/n. (CONC); Cordillera de Piuchén por Piruquina, Isla de Chiloé, 28-X-1970, R. Gajardo \& A. Troncoso (CONC); Río Abtao, Cordillera de Piuchén, isla Grande de Chiloé, 15-II-1983, C. Villagrán 4926 (CONC).

\section{Gaultheria antarctica Hook. f.}

J.D. Hooker, Fl. Antarct. 116. Feb-Mart. 1846. Typus. J. D. Hooker s.n. "Hermite island, cape Horn".

Arbutus serpyllifolia Lam., Encycl. 1:228. 1783; Pernettya serpyllifolia (Lam.) DC., Prodr. (DC.) 7(2): 587.1839 [late Dec 1839]; Gaultheria microphylla Hook. f., Fl. Antarct. 327. Feb-Mart. 1846; Pernettya hookeri Nied., Bot. Jahrb. Syst. 11: 172, 190, 224. 1889; Gaultheria serpyllifolia (Lam.) Skottsb., Kongl. Svenska Vetenskapsakad. Handl. 56(5): 282, 1916, non Pursh, 1814.

Subarbusto de hasta $10 \mathrm{~cm}$ de altura, con ramitas delgadas y procumbentes. Hojas de (3) 4-7 x 1,5-3 (5) mm, con pecíolo de $0,5 \mathrm{~mm}$, glabras, laxas, coriáceas y lustrosas, lámina ovado-oblonga, algo aguda, margen engrosado, con 4-6 (8) dientes pequeños y redondeados a cada lado, nervaduras apenas visibles. Especie dioica. Flores unisexuales, solitarias, axilares, pedicelo de $c a .0,5 \mathrm{~mm}$ en las flores femeninas y de 1-1,5 mm en las masculinas; rodeadas en la base por 6 pequeñas brácteas, las dos superiores opuestas e insertas inmediatamente debajo del cáliz; éste 5-lobulado, lóbulos de $c a .1,3 \mathrm{~mm}$, triangulares y obtusos. Flores masculinas con corola de $3 \mathrm{~mm}$, campanulado-esférica; estambres 10 , todos del mismo tamaño con anteras papilosas, de $0,5 \mathrm{~mm}$ de longitud. Flores femeninas con corola de $2 \mathrm{~mm}$, gineceo con el ovario fértil. Fruto, una cápsula de $4,5 \mathrm{~mm}$ de diámetro, globosa hasta turbinada, rodeada por los sépalos de color rojo, engrosados y carnosos, que dejan visibles el estilo y el ápice (Fig. 1b).

Distribución geográfica: Especie nativa de Chile y Argentina. Se encuentra en ambas cordilleras, desde la provincia de Valdivia hasta la Región de Magallanes. Crece frecuentemente en turberas o como epífita.

ObSERVAción: En ausencia de frutos se confunde con $G$. pumila var. pumila e incluso con Myrteola nummularia O.Berg (Myrtaceae), con la que comparte el tipo de ambiente.

Materiales estudiados: Región de los Ríos: Prov. de Valdivia, Cordillera Pelada, cerro Mirador, $1040 \mathrm{~m}$, 01-II-1965, M. Ricardi, C. Marticorena \& O. Matthei 1196 (CONC). Región de Los Lagos: Prov. de Chiloé, Melinka, 1873, A. Guajardo s/n. (SGO); Archipiélago de las Guaytecas, Melinka, 07-II-1957, M. Ricardi \& C. Marticorena 4059 (CONC). Prov. Palena, P. N. Hornopirén, carretera Austral. 500 m, 01-III-1993, R. Godoy, HildebrandVogel \& A. Vogel 126 (CONC); Huinay, 950 m, 24-II2008, Flores \& Soto 40 (CONC). Región de Aysén: Prov. de Aysén, P.N. Laguna San Rafael, Istmo de Ofqui, 03-II1988, E. Pisano 6328 (CONC). Prov. Última Esperanza, P. N. Torres del Paine, $2 \mathrm{~km} \mathrm{~S}$ refugio Zapata, $250 \mathrm{~m}$, 01-III1998, Elvebakk 98-297 (CONC). Región de Magallanes: Prov. de Magallanes, Bahía Sarmiento, 21-III-1945, Biese 1407 (SGO); Punta Arenas, Pampa Colorada, 25-IV-1955, O. Magens s/n. (CONC, 19085); Isla Capitán Aracena, bahía Morris, 09-XII-1971, Pisano 3352 (CONC); Fiordo Nevado, Isla Santa Inés, Bahía Havergal, 24-II-1990, E. Pisano \& J. M. Henríquez 6670 (CONC).

\section{Gaultheria caespitosa Poepp. et Endl.}

Poeppig et Endlicher, Nov. Gen. Sp. Pl. 1:25.1835. "Crescit in Chile australis summis Andium jugis ad Antuco et Chillán".

Pernettya minima Phil., Linnaea 29:11.1858; Gaultheria minima (Phil.) Sandwith, Field Notes Pl. Collect. Comber 69. 1928. 
Subarbusto, tallos rastreros, radicantes, de $3-5 \mathrm{~cm}$ de altura, ramas glabras o apenas pubescentes. Hojas de 2-3 (5) x 1,5$2 \mathrm{~mm}$, densas, coriáceas, algo lustrosas y glabras, lámina elíptico-oblonga, obtusa, atenuada en un pecíolo muy corto; enteras o con 1-3 dientes redondeados, débiles, a cada lado, nervios apenas visibles. Especie ginodioica (Hermann \& Cambi 1992). Flores unisexuales; solitarias, axilares, pedunculadas, glabras y sin brácteas, con dos bractéolas opuestas en la base del pedicelo; éste de 0,5-1 mm, en ambos tipos de flores. Cáliz tetrámero, lóbulos de ca.1,5 $\mathrm{mm}$, aovado-triangulares. Flores masculinas con corola de 4-5 mm, urceolado-cilíndrica, con 4 (rara vez 5) lóbulos de ca. $1 \mathrm{~mm}$; ovario de $1 \mathrm{~mm}$, estéril. Las flores femeninas de 3-4 mm, ampliamente urceoladas, con 4 (rara vez 5) lóbulos; estambres estériles y gineceo con ovario fértil. Fruto, una cápsula envuelta por los sépalos que se tornan carnosos y adquieren un color blanco cuando maduran (Fig. 1c).

DistribuCión GeOgráfica: especie nativa de Chile y Argentina. En Chile se encuentra desde la cuenca del río Aconcagua (provincia de San Felipe) hasta la del río Cuervo (provincia de Aysén). En el área norte de la distribución crece sólo en las vegas altoandinas.

Por el tamaño reducido de su hábito y de sus hojas, en ausencia de frutos, puede ser confundida con las otras Gaultheria de tamaño pequeño tales como G. antarctica, $G$. pumila var. leucocarpa y G. pumila var. pumila.

Materiales estudiados: Región de Valparaíso: Prov. de Los Andes, río Colorado, cuenca del Aconcagua, 3480 m, 19-II2002, S. Teillier 5108 (CONC); Laguna Turquesa, cuencas del estero Castro y del Río Blanco, 28-IV-2003, G. Mieres s/n. (CONC). Región Metropolitana, Prov. de Santiago, S.N. Yerba Loca, vega entre Casa de Piedra Carvajal y cerro La Paloma, 3180 m, 14-II-1999, M. T. Kalin-Arroyo \& Humaña, 99-1727 (CONC). Región del Bío Bío: Prov. Bío-Bío, R.N. Ralco, Pelado Mallín, 1830 m, II-2002, M. Mihoc, Jiménez, González \& E. Badano 4297 (CONC). Región de la Araucanía: Prov. de Malleco, Lonquimay, paso de Pino Hachado, 1910 m, 7-II-1991. B. Ruthsatz 766 (CONC). Región de Los Lagos: Prov. Osorno, Antillanca, 1390 m, 6-I-1981, F. Schlegel 7323 (CONC). Región de Aisén: Prov. Aisén, Lago Meullín, Río Cuervo, 500 m, 19-I2007. N. García 3967 (CONC).

4. Gaultheria insana (Molina) D.J.Middleton

D. J. Middleton, Edinburgh J. Bot. 47(3): 297. 1990.

Basiónimo: Hippomanica insana Molina, Sag. Stor. Nat. Chili 126. 1782.

Arbutus furiens Hook. \& Arn., Bot. Beechey Voy. 33.1830; A. punctata Hook. \& Arn., Bot. Beechey Voy.33.1830;
Gaultheria furiens (Hook. \& Arn.) Hook. \& Arn., J. Bot. (Hooker) 1: 281.1834; G. punctata (Hook. \& Arn.) Hook. \& Arn, J. Bot. (Hooker) 1: 281. 1834; A. vernalis Poepp. \& Endl., Nov. Gen. I. 26. t. 42.1836; G. vernalis (Poepp. \& Endl.) Kunze, in DC. Prodr. 7(2): 594.1839; Pernettya furiens (Hook. \& Arn.) Klotzsch, Linnaea 24: 83. 1851; P. punctata (Hook. \& Arn.) Klotzsch, Linnaea 24: 83.1851; P. vernalis (Poepp. \& Endl.) Phil., Anales Univ. Chile 18 (1):65.1861; P. melanocarpa Phil., Anales Univ. Chile 65: 59. 1884; P. insana (Molina) Gunckel, Not. Mens. Mus. Nac. Hist. Nat. 17 (197): 6. 1972.

HUED-HUED

Arbusto de 1-5 m de altura, ramas delgadas y erguidas, las jóvenes finamente pubescentes, laxamente cubiertas con setas más o menos adpresas, de color negruzco-rojizo. Hojas pecioladas, subcoriáceas, cubiertas en ambas caras por setas de $c a$. $1 \mathrm{~mm}$, laxas o más o menos adpresas, de color castaño, caedizas que dejan puntos castaño-rojizos al desprenderse; envés pubescente; lámina de 25-50 (85) x 15-25 (40) mm, elíptica hasta oblongo-elíptica, más o menos anchamente cuneada y atenuada gradualmente hacia el ápice, terminando en una punta glandular algo obtusa; margen frecuentemente revoluto con dientes pequeños y redondeados. Especie dioica. Flores unisexuales, dispuestas en racimos densos, de 20-30 (50) mm, con 6-20 flores blancas. Los pedúnculos y los pedicelos a veces densamente pubescentes y siempre cubiertos por pelos rígidos, rojizos y ramosos en su base. Los pedicelos están provistos de una bráctea pequeña en su base y de dos bractéolas subopuestas en su cuarto o tercio inferior. Cáliz profundamente 5-partido, lóbulos de 2,5 mm, alargado-triangulares, ciliados y pubescentes. Flores masculinas con corola de $7 \mathrm{~mm}$, oblongo-urceolada y pilosa en su cara interna; estambres 10 , 5 de ellos más cortos; anteras de 1,2-2 mm, fértiles; gineceo con ovario menor y estéril. Flores femeninas con corola de $6 \mathrm{~mm}$, urceolada y pilosa en su cara interna; estambres, con las anteras estériles; gineceo con ovario glabro, fértil, estilo de 3-4,5 mm con el estigma bien desarrollado. Fruto, una baya de 5-6 mm diámetro, seca y globosa; de color blancorojizo, a veces, purpúreo-negruzco; sépalos ni acrescentes, ni carnosos (Fig. 1d).

Distribución GeOgráfica: especie nativa de Chile y Argentina. En el país, crece en forma aislada en Paposo (provincia de Antofagasta) y luego desde la provincia de Constitución (VII Región) hasta la Región de Magallanes (XII). En Paposo es muy escasa y crece en el matorral costero del oasis de neblinas; más al sur crece en diversos tipos de bosques y en varios tipos de matorrales primarios o secundarios.

En ausencia de frutos se puede confundir con G. renjifoana, sin embargo la pilosidad de las hojas y las cicatrices en las 
hojas viejas de G. insana las separan con facilidad.

Materiales estudiados: Región de Antofagasta: Prov. de Antofagasta, quebrada Sepultura, 850 m, 23-I-1990, J. Flores s/n (SGO 111134); quebrada Sepultura, Cordillera de la Costa, 840 m, 03-X-1991, M. Quezada \& E. Ruiz 169 (CONC). Región del Maule: Prov. Talca, La Mina, camino a El Melado, 1500 m. 17-XII-1953, M. Ricardi 2794 (CONC). Prov. de Cauquenes, Cauquenes, litoral, 160 m, 15-XI-1958, F. Schlegel 1795 (CONC). Región del BíoBío: Prov. de Concepción, in rupestribus Chili. Australis \& Talcahuano. Sept. lect. Poeppig 119 (Fototipo No 4600, SGO, tipo de Arbutus vernalis Poepp.); Concepción, Cerro Caracol. 9-X-1934, Junge s/n (CONC); Boca del Bío Bío, 12-X-1953, B. Sparre 9960 (CONC); Colcura, cajón del Ciprés, 300 m. C. Marticorena, M. Quezada \& R. Rodríguez 1052 (CONC); Chivilingo norte, $180 \mathrm{~m}, 05-\mathrm{XII}-2000$, M. Baeza \& R. Rodríguez 2412 (CONC). Prov. de Arauco, cerros de Villagrán, Colcura, III-1884, R.A. Philippi (SGO, tipo de Pernettya melanocarpa Phil.). Región de la Araucanía: Prov. de Malleco, Angol, 4,5 km al oeste, 02XI-1967, O’Brien 82 (CONC); P.N. Nahuelbuta, alto Los Cóndores. 13-XII-1983, O. Matthei \& M. Quezada 55-a (CONC). Región de los Ríos: Prov. de Valdivia, Chaigüín, Los Alerzales, 800 m, 17-XII-1953, L. Smith \& B. Sparre 265 (CONC). Región de Los Lagos: Prov. de Llanquihue, Puerto Montt, Laguna Mansa, 25-II-1948, A. Pfister s/n. (CONC). Prov. de Chiloé, Melinka, 07-02-1957, M. Ricardi \& C. Marticorena 4057 (CONC). Región de Aysén: Prov. Aysén: Isla Clemente, canal Millabu, 22-VII-1970, O. Parra 83 (CONC); P.N. Laguna de San Rafael, 80 m, 31-I-1959, F. Schlegel 1950 (CONC). Región de Magallanes: Prov. Última Esperanza, Puerto Edén, isla Wellington, X-1933, Junge $s / n$. (CONC).

5. Gaultheria mucronata (L.f.) Hook. et Arn.

Hooker et Arnott, J. Bot. (Hooker) 1: 281. 1834.

Basiónimo: Arbutus mucronata L.f., Suppl. Pl. 239. 1782. "Habitat in Tierra del Fuego"

Pernettya mucronata (L.f.) Gaudich. ex Sprengel, Syst. Veg. 4 (2). Cur. Post.158. 1827; Gaultheria myrtilloides Hook. \& Arn. var. minor Hook. \& Arn., J. Bot. (Hooker) 1: 281.1834; Arbutus rigida Banks, Bot. Antarct. Voy. I. (Fl. Antarct.) 2: 326. 1846; P. mucronata (L.f.) Gaudich. ex Spreng. var. microphylla Hombr., tab.22.1852; P. oblongifolia Hombr. tab. 22 bis.1852; P. ovalifolia Hombr., Voy Pôle Sud II: Dicot. Phan. tab. 22 bis. 1852; P. rupicola Phil., Linnaea 29:10. 1857-1858; P. litoralis Phil., Anales Univ. Chile 27 (2):319.1865; P. parvifolia Phil. Anales Univ. Chile 90:194. 1895; P. mucronata (L.f.) Gaudich. ex Spreng. var. rupicola (Phil.) Reiche, Fl. Chile 5 :74. 1910. P. mucronata (L.f.) Gaudich. ex Spreng. var. microphylla (Phil.) Reiche,
Fl. Chile 5 :75. 1910. P. mucronata (L.f.) Gaudich. ex Spreng. var. parvifolia (Phil.) Skottsb, Kongl. Svenska Vetenskapsakad. Handl. 56 :283. 1916.; G. mucronata (L.f.) Hook. et Arn. var. microphylla (Hombr.) D.J. Middleton, Edinburgh J. Bot. 47 (3): 298.

\section{CHAURA}

Arbusto de 20-80 (hasta 2,5 m) de altura, erguido, con ramas robustas; ramillas glabras o pubescentes y laxamente setosas. Hojas pecioladas, duras y coriáceas, glabras; lámina de 1-2 x 0,4-0,6(1) cm, aovado-elíptica hasta aovado-oblonga, engrosada en el borde y provista de 4-5 dientes redondeados gruesos a cada lado; ápice atenuado y terminado en un mucrón rígido de $c a .1 \mathrm{~mm}$. Especie dioica. Flores unisexuales, solitarias, axilares, pedicelo de 5-10(12) $\mathrm{mm}$, finamente pubescente y laxamente setoso, rodeadas en la base, por varias brácteas pequeñas y dos bractéolas casi opuestas. Cáliz profundamente 5-partido, lóbulos de $2 \mathrm{~mm}$ angostamente triangulares, algo agudos. Flores masculinas con una corola de $c a .5 \mathrm{~mm}$, campanulada; androceo con 10 estambres, anteras de $1 \mathrm{~mm}$, filamentos de 1,2-1,5 mm; gineceo con ovario de $1,2 \mathrm{~mm}$, piriforme, estéril. Flores femeninas con una corola de $c a .4 \mathrm{~mm}$, urceolado-cilíndrica; estambres estériles; gineceo con ovario fértil, estigma con 5 lóbulos bien desarrollados. Fruto, una baya de 6-8 (10) mm de diámetro, algo deprimida, casi globosa, rosada, a rosado oscura, raro blanca, cáliz ni acrescente ni carnoso (Fig. 2a).

Distribución GeOgráfica: Especie nativa. Crece desde Corral (provincia de Valdivia) hasta la Región de Magallanes. Se encuentra en los bosques de Nothofagus siempreverdes y en los matorrales costeros primarios y secundarios. De acuerdo con la disponibilidad de colecciones, es muy escasa en el litoral de Valdivia y Osorno.

La var. microphylla se estableció a partir del ejemplar-tipo recolectado en la costa de Punta Arenas con hojas mucho más pequeñas que el tipo de G. mucronata. No se han vuelto a recolectar especímenes similares; posiblemente se trata de algún ecotipo local o algún ejemplar enfermo.

ObSERVACIONES: En ausencia de frutos se puede confundir con G. phyllireifolia; en presencia de ellos se diferencia de $G$. angustifolia por el ancho de la lámina de las hojas y de G. poeppigii, por la presencia de los mucrones fuertes en el extremo de las hojas.

\section{Materiales estudiados:}

Región de Los Ríos: Prov. de Valdivia, Corral, R. A. Philippi (SGO, tipo de Pernettya rupicola Phil.); Quitaluto, Corral, 23-III-1930, H. Gunckel 1432 (CONC). Prov. de La Unión, in arenosis maritimis Hueicolla, XI-1864, F. Philippi (SGO, tipo de Pernettya litoralis Phil.). Región de Los Lagos: Prov. de Chiloé, Quilán, Cucao, 01-I-1932, A. Pfister s/n. (CONC); 
río Gamboa, Castro, 15-I-1952, Bartulín (CONC); Abtao, cerros costeros, 16-II-1983, C. Villagrán 4965 (CONC); Isla Alao, 06-II-1983, I. Meza \& G. Valenzuela 5198 (CONC). Región de Aysén: Prov. Aysén, Isla Clemente,Canal Millabu, 22-VII-1970, O. Parra 85 (CONC). Prov. Aysén, entre Cisne Medio y La Tapera, 20-III-1985, T. Stuessy, Furlow, E. Ruiz \& Bustos 7496 (CONC). Prov. Capitán Prat, Tortel, desembocadura del Baker, 05-VIII-1976, R. Rodríguez 836 (CONC); Ventisquero Soler 500 m, 24-III-1967, Seki 556 (CONC); Los Ñadis, 145 m, 07-XII-2006, A. Marticorena, Ramírez, Martínez \& Vidal 1012 (CONC). Región de Magallanes: Prov. de Última Esperanza, Isla Guarello,
13-XI-1975, Moyano (CONC); P. N. Torres del Paine, Río Grey, 20-XII-1987, O. Dollenz 1400 (CONC); Fiordo Peel, río al E del Cerro Aguilera, 15-XII-1985, E. Pisano 6044 (CONC). Prov. de Magallanes, detroit de Magellan, Commerson ex herb. Gaudichaud (CONC); Estrecho de Magallanes, Punta Arenas, verano de 1864-5, s/c (SGO, tipo de P. parvifolia Phil.); Punta Arenas, I-1950, K. Behn (CONC); seno Skyring, III-1954, Magens 352 (CONC). Prov. Antártica Chilena, J.R. Forster, Isla Hermite, Cabo de Hornos, Exp. Antarctica ex Herb. Hooker (CONC), Isla Navarino, I-1966, Tsuji 235 (CONC).
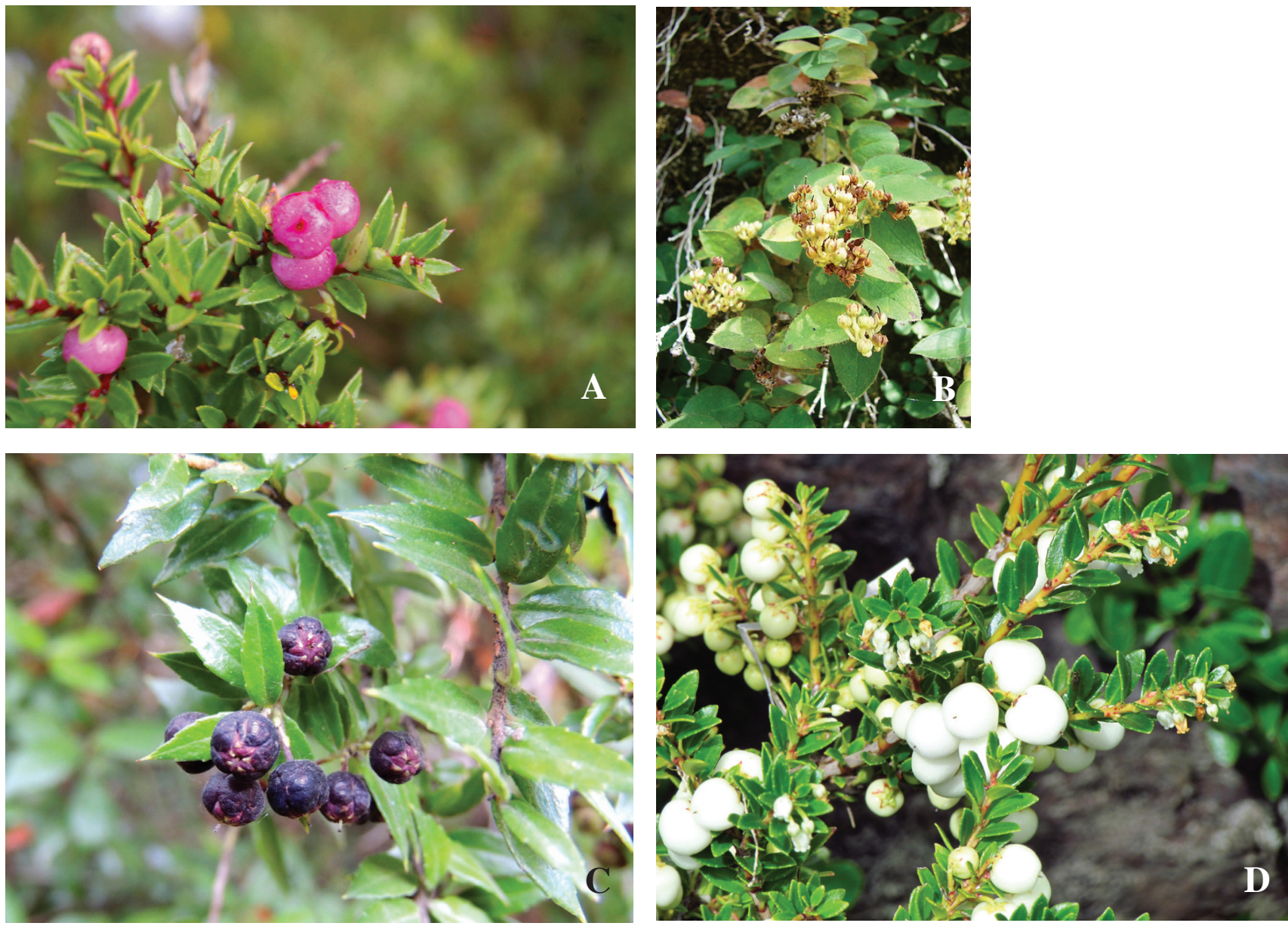

Figura 2. a. Gaultheria mucronata (L.f.) Hook. et Arn., rama con frutos. Camino al lago Pastahue, isla Grande de Chiloé (Fotografía del autor); b. Gaultheria nubigena (Phil.) Burtt et Sleumer, planta florida. Ojos del Caburgua, provincia de Cautín (Fotografía de Patricio Novoa); c. Gaultheria phyllireifolia (Pers.) Sleumer, rama con frutos. Reserva Biológica de Huilo Huilo (Fotografía de Javiera Delaunoy); d. Gaultheria poeppigii DC., rama con frutos. Reserva Biológica de Huilo Huilo,volcán Mocho-Choshuenco (Fotografía del autor).

Figure 2. a. Gaultheria mucronata (L.f.) Hook. et Arn., branch with fruits. Road to Pastahue lake, isla Grande de Chiloé (Photo by the author); b. Gaultheria nubigena (Phil.) Burtt et Sleumer, a flowering plant. Ojos del Caburgua, provincia de Cautín (Photo: Patricio Novoa); c. Gaultheria phyllireifolia (Pers.) Sleumer, branch with fruits. Huilo Huilo Biological Reserve (Photo: Javiera Delaunoy); d. Gaultheria poeppigii DC., branch with fruits. Huilo Huilo Biological Reserve, Mocho-Choshuenco volcano (Photo by the author). 
6. Gaultheria nubigena (Phil.) Burtt et Sleumer Burtt et Sleumer, Notizbl. Bot. Gard. Berlin-Dahlem 13: 207. 1936.

Basiónimo: Pernettya nubigena Phil., Anal. Univ. Chile 18: 64. 1861.

Subarbusto, tallos colgantes, postrados o procumbentes, delgados y glabros. Hojas glabras en la haz y finamente pubescente en el envés, lámina de $(0,7) 1$-1,6 $(2,5)$ x $(0,4) 0,8$ $1,2(1,9) \mathrm{mm}$, aovada hasta redondeado-aovada; redondeada o débilmente cordiforme en la base, ápice agudo; borde delicadamente aserrado con los dientecillos terminados en un cilio muy evidente. Flores hermafroditas, dispuestas en cimas axilares y terminales de hasta $2 \mathrm{~cm}$, con 5-15-flores, pedúnculo finamente pubescente; pedicelo de 3-4 $\mathrm{mm}$ en la axila de una bráctea, con dos bractéolas opuestas en su base. Corola blanca con las nervaduras rosadas, de $5 \mathrm{~mm}$, urceolado-cilíndrica; androceo con 10 estambres, 5 largos y 5 cortos, los más cortos alcanzan la mitad de la corola; gineceo con ovario de $1 \mathrm{~mm}$, glabro, estilo es de $2,5 \mathrm{~mm}$ y estigma obtuso. Fruto, una cápsula coriácea, los lóbulos del cáliz muy poco engrosados, patentes durante la madurez (Fig. 2b).

Distribución GEOGRÁFICA: Especie nativa de Chile y Argentina; en Chile crece entre el Parque Nacional Conguillío (provincia de Cautín) y la cordillera del seno de Reloncaví (provincia de Llanquihue). Al parecer sería una especie andina, higrófila, saxícola y umbratícola (esciófila). Planta bastante rara en su distribución y muy poco coleccionada. Necesita un estudio más acabado para conocer su estado de conservación. Hechenleitner et al. (2005) sugieren que sería una especie amenazada. En Argentina, también es rara, y se ha propuesto clasificarla como vulnerable por el escaso número de poblaciones y ejemplares (Hermann \& Cambi, 2006).

ObSERVACIONEs: Según la interpretación de Bush et al. (2009) el fruto sería una cápsula con sépalos no acrescentes.

Materiales estudiados: Región de la Araucanía: Prov. de Cautín: Cupulhue, Volckmann s/n. (SGO); P. N. Conguillío, path to Sierra Nevada, 26-I-2004, Brownless et al. 962 (CONC, SGO). Región de Los Lagos: Prov. de Llanquihue, zona alpina de los cerros que rodean el Seno de Reloncaví, Pearce (SGO, tipo de Pernettya nubigena Phil.); P. N. Vicente Pérez Rosales, Cerro Puntiagudo, 750 m, 30-I1975, C. Villagrán, I. Meza \& A. Troncoso s/n. (SGO).

7. Gaultheria phillyreifolia (Pers.) Sleumer

Sleumer, Notizbl. Bot. Gard. Berlin-Dahlem 13: 207. 1936.

Basiónimo: Arbutus phillyreifolia Pers., Syn. Pl. 1:483. 1805. "Hab. in Peru. Herb Jussieu”.
Pernettya phillyreifolia (Pers.) DC., Prodr. 7:587. 1839; G. myrtilloides Hook. \& Arn., J. Bot. (Hooker) 1: 281. 1834; G. mucronata Phil. Linnaea 29: 12. 1857-58; G. florida Phil. Anal. Univ. Chile 90: 192. 1895; G. lanceolata Phil., Anal. Univ. Chile 90-193.1895; P. philippii Gand., Bull. Soc. Bot. France. 60: 24. 1913; G. myrtilloides Hook. \& Arn. var. racemosa (Phil.) Reiche, Anales Univ. Chile 117: 498. 1906; G. phillyreifolia (Pers.) Sleumer var. florida (Phil.) Kausel, Revista Univ. (Santiago) 34: 172. 1949.

\section{Chaura.}

Arbusto de 0,8-1,8 (2,5) $\mathrm{m}$ altura, ramillas pubescentes, provistas de setas densas, de color castaño-rojizas. Hojas coriáceas, glabras, de (10) 12-19 (28) x 4-6 mm, aovadooblongas, rara vez lanceoladas o aovadas, cortamente pecioladas; base cuneada hasta redondeada, ápice acuminado prolongado en un mucrón punzante, sobre todo en las hojas jóvenes, borde aserrado con (4) 6-8 (12) dientes a cada lado, que terminan en una seta glandular caediza, la cara superior con el borde engrosado y el nervio medio marcadamente prominente. Especie dioica. Flores unisexuales, generalmente solitarias, dispuestas en las axilas de las hojas superiores, disminuyendo en tamaño en dirección al ápice, algunas veces forman cimas axilares con 3-10-flores; pedicelos de 5-16 $\mathrm{mm}$, delgados, nutantes y provistos de 2-6 (9) bractéolas en la mitad inferior o en toda su longitud. Flores masculinas con cáliz de $2 \mathrm{~mm}$, cuyos lóbulos son agudamente triangulares; corola de $4 \mathrm{~mm}$, cónico-urceolada y pilosa en su cara interna; androceo con 10 estambres desiguales, anteras fértiles; gineceo con ovario residual, estéril. Las femeninas, con corola de $3 \mathrm{~mm}$ y ovario fértil. Fruto, una cápsula coriácea, de color castaño-claro, dehiscente desde el ápice, rodeada casi completamente por los sépalos, que se tornan carnosos y de un color negro-violáceo hacia la madurez (Fig. 2c).

Distribución GeOgRÁfiCA: Especie nativa de Chile y Argentina. Crece desde las Sierras de Bellavista (provincia de Colchagua) hasta en la Región de Magallanes. Es uno de los arbustos dominantes en los matorrales secundarios que suceden a la tala de los bosques de Nothofagus dombeyii.

\section{OBSERVACIONES:}

Respecto de las variedades establecidas por Reiche (1905) y Kausel (1949), hace falta un trabajo más detallado para dilucidar si las variaciones en que se fundan son o no clinales.

De acuerdo con la información que se dispone para la flora del Perú (Brako \& Zarucchi 1993) es evidente que el tipo Arbutus phyllireifolia Pers. no fue coleccionado en ese país, como erróneamente aparece en su etiqueta. Según el sitio web del herbario del Museo Nacional de Historia Natural de París el colector sería J. Dombey. En el mismo sitio la autoría del binomio se la atribuyen erróneamente a Jussieu. 
Kausel (1949) ya llamaba la atención sobre la posibilidad que el tipo haya sido coleccionado en el área de Talcahuano (Región del Bío-Bío).

Circulan algunos fototipos de plantas determinadas por Philippi como Gaultheria floribunda Phil. (sitio web del Field Museum: http://emuweb.fieldmuseum.org/botany/ berResultsList.php)

Muñoz Pizarro (1960), sin embargo, no cita a $G$. floribunda entre las especies descritas por Philippi. En el mismo trabajo figura $G$. florida Phil. y se le asignan 5 ejemplares existentes en SGO como co-tipos o isotipos. Kausel (1949), también acepta G. florida Phil. y la utiliza como basónimo de su variedad G. phyllireifolia var. florida (Phil.) Kausel.

En ausencia de frutos es difícil distinguirla de $G$. mucronata, aunque generalmente el mucrón foliar alcanza a casi un tercio del largo de la lámina, por lo que se ve mayor.

G. phyllireifolia es más frecuente y abundante al norte de la provincia de Chiloé, en tanto que G. mucronata es más común y abundante al sur de la isla Grande de Chiloé.

Materiales estudiados: Región de O'Higgins: Prov. Colchagua, fundo Bellavista, 08-XII-1960, Hochstetter s/n. (CONC). Región del Maule: Prov. Curicó, Radal Siete Tazas, Parque Inglés, 06-IX-1985 Nowicki 03 (CONC). Prov. de Linares, Lago Bullileo, XII-1989, O. Zöllner 5366 (CONC). Región de la Araucanía: Prov. de Malleco, Capitán Pastene, 400 m, 09-XII-1934. MONTERO 2239 (CONC); camino Termas de Tolhuaca, Laguna de Malleco, $1700 \mathrm{~m}$, 10-I-1996, A. Marticorena, N. Mazzeo, Dardano, Cazals 361 (CONC). Prov. de Cautín, Santa Elvira de Trancura, 590 m, 23-XII-2001, C. Aedo, 7247 (CONC). Región de Los Ríos: Prov. Ranco, M. N. Alerce Costero, altos del Mirador, 5-II-1988, Gardner 4067 (CONC); camino de La Unión a Hueicolla, km 50, 250 m, 02-II-1986, Pacheco \& Pantoja 1158 (CONC). Región de Los Lagos: Prov. Osorno. Gay 1463. (SGO, tipo de G. mucronata Phil.); Osorno, Islote Rupanco, II-1978, R. Godoy s/n. (SGO). Prov. Llanquihue, Puerto Octay, Lago Llanquihue, E. Pisano 1173. 9-II-1942 (CONC). Prov. Chiloé, Ancud, I-1858, R.A. Philippi. (F, SGO, ¿tipo de G. florida Phil.?). Prov. de Palena, CerroYate. 1871, Juliet s/n. (SGO, tipo de G. lanceolata Phil.). Región de Aysén: Prov. de Aysén, P. N. Laguna San Rafael, cascada Río Saltón. 01-II-1988 E. Pisano 6268 (CONC). Región de Magallanes, Prov. útima Esperanza, Puerto Edén, Isla Wellington, 16-XII-1988, E. Pisano 6449 (CONC).

\section{Gaultheria poeppigii DC.}

De Candolle, A. P., Prodr. 7 (2): 593. 1839.

Gaultheria myrtilloides Poepp. \& Endl., Nov. Gen. Sp. Pl. 1: 25. t. 41. 1836. nom. illeg; Pernettya myrtilloides Zucc. ex Steudel, Nomencl. Bot. Ed. 2,2:306. 1841; P. poeppigii (DC.) Klotzsch, Linnaea 24: 83. 1851; P. buxifolia Phil.,
Anal. Univ. Chile 43:508. 1873; P. patagonica Speg., Revista Fac. Agron. Univ. Nac. La Plata 3: 547. 1897; P. philippiana Speg., Rev. Agron. La Plata, 548. 1897; P. phillyreifolia (Pers.) DC. var. araucana Kuntze, Revis. Gen. Pl. 3[3]: 192. 1898; P. leucocarpa DC. var. buxifolia (Phil.) Reiche, Anales Univ. Chile 117: 493. 1905; P. poeppigii (DC.) Klotsch var. nana Sleumer, Lilloa 25: 549. 1952; $P$. myrtilloides Zucc. ex Steud. var. nana (Sleumer) Sleumer, Bot. Jahrb. Syst. 104:473.1985; G. poeppigii DC. var. nana (Sleumer) D.J. Middleton, Edinburgh J. Bot. 47 (3):298.

CHAURA, SHAL, SHEÚKK, GUS, AMAIN-NGUSH

Arbusto erguido y entonces, de 30-100 (150) cm de altura, o tendido $(10-20 \mathrm{~cm})$, denso; ramillas finamente pubescentes y laxamente setosas. Hojas brevemente pecioladas; las más jóvenes fina y laxamente pubescentes, especialmente en los bordes; lámina de (8) 10-20 x 3-5 (7) mm, ovado-elíptica anchamente oblongo-elípticas, algo aguda a causa de la costilla media algo prolongada, margen engrosado con 4-5 (7) dientes redondeados a cada lado. Especie dioica. Flores unisexuales, solitarias, axilares; pedicelos de 4-5 mm, pubescentes, a veces, con glándulas estipitadas aisladas y caedizas, en la base están rodeados de 4 brácteas pequeñas y 2 bractéolas. Cáliz profundamente 5-partido, lóbulos de 1,5-2 mm, triangulares. Corola de $c a .3 \mathrm{~mm}$, urceolada. Las flores masculinas tienen 10 estambres, 5 más cortos, con anteras de 1-1,2 mm, anchamente ovoide-oblongas y filamentos de 1-1,5 mm; gineceo con ovario estéril. Las flores femeninas tienen un androceo estéril y el gineceo con ovario fértil, de 1,5 $\mathrm{mm}$ globoso y piriforme. Fruto una baya de 4-6 mm de diámetro, globosa o algo deprimida, de color blanco, rosado o morado (Fig. 2d).

Distribución GeOgRÁfICA: Especie nativa de Chile y Argentina. En Chile crece desde la cordillera de la provincia de Talca hasta el P.N. Laguna San Rafael en la Región de Aysén.

Crece preferentemente en el ámbito de los bosques de montaña de Nothofagus dombeyii y Nothofagus pumilio, también en los matorrales de Nothofagus antarctica y en el margen inferior del piso andino.

ObSERVACIONes: Se encuentran numerosos ejemplares que podrían ser híbridos entre esta especie y G. pumila (L. f.) Middleton, con la que frecuentemente entra en contacto en la zona andina. Los ejemplares se reconocen por tener un tamaño menor, hábito postrado, hojas más cortas y frutos de color rosado, muy pálido. Algunos de ellos se determinaron como G. poeppigii var. nana.

Materiales estudiados: Región del Maule: Prov. de Talca, Altos de Vilches, camino a Laguna El Alto, 1800 m. 29I-2000, V. Finot \& P. López 1720 (CONC). Región del Bío Bío: Provincia de Ñuble, Termas de Chillán, II-1933, 
Jaffuel 2755 (CONC); Nevados de Chillán, Pirigallo, 2000 m, 06-XII-1992, R. Rodríguez \& A. Marticorena 2995 (CONC). Prov. Bío Bío, volcán Antuco, 13-X-1969, Weldt 183 (CONC); Laguna El Barco, lado este, $1300 \mathrm{~m}$, M. Mihoc, Jiménez, González \& E. Badano 4561 (CONC); P. N. Laguna del Laja, sendero desde Los Zorros al pie de la Sierra Velluda, 24-I-2001, M. Baeza, M.J. Parra \& Torres 3220 (CONC). Región de la Araucanía: Prov. de Malleco, Nahuelbuta, Volckmann (SGO, tipo de Pernettya buxifolia Phil.); Laguna Icalma, 1300 m, 12-I-1947, A. Pfister s/n. (CONC). P. N. Nahuelbuta, 1000 m, 05-XII1964, G. Montero 7003 (CONC); Trongol Alto, loma El Consorcio, 180 m, II-2002, M. Baeza \& Kottirsch 1372 (CONC). Prov. de Cautín, Volcán Villarrica, 1250 m, 18-I1948, A. Pfister s/n. (CONC); Volcán Llaima, 2000 m, 12III-1972, Duek \& Inostroza (CONC). Región de los Ríos: Prov. Valdivia, Cordillera Pelada, cerro Mirador, 1040 m, 01-II-1965, M. Ricardi, C. Marticorena \& O. Matthei 1208 (CONC); Choshuenco, Chan Chan, 26-II-1980, G. Montero 11649 (CONC). Región de los Lagos: Prov. Osorno, Antillanca, 1050 m, III-1967, Zollitsch 92-A (CONC). Prov. de Llanquihue, P. N. Pérez Rosales, laderas del Volcán Osorno, 200 m, 10-I-1986, Gardner 3435 (CONC). Prov. Chiloé, Lago Río Negro, cerros al este, 200 m, 11-I-1986, C. Villagrán, Águila \& R. Leiva 6866 (CONC). Región de Aysén: Prov. Aysén, Lago Yulton, orilla W-NW, 490 m, 20-I-2007, N. García 3990 (CONC); P.N. Laguna San Rafael, Río Huala, 5-II-1959, F. Schlegel 2078 (CONC); río Exploradores, ventisquero Circo, 150 m, 27-II-2010, Seki 215 (CONC).

Supuestos híbridos G. poeppigii x G. pumila Región del Bío Bío: Prov. Ñuble, Termas de Chillán, valle de las Nieblas, 2000 m, 17-I-1945, A. Pfister s/n. (CONC). Prov. de Bío Bío, R.N. Ralco, Volcán Callaqui, 1735 m, II2002, M. Mihoc, Jiménez, González \& E. Badano, 4340 (CONC). Región de la Araucanía: Prov. Cautín, Pucón, II, 1935, A. Pfister s/n. (CONC).

9. Gaultheria pumila (L.f.) D.J. Middleton

D. J. Middleton, Edinb. J. Bot. 47 (3): 298.1990.

Basiónimo: Arbutus pumila L.f., Suppl. Pl.: 239. 1781. "Habitat in Tierra del Fuego".

Pernettya empetrifolia (Lam.) Gaudich., Ann. Sci. Nat. (Paris) 5: 102. 1825; P. pumila (L. f.) Hook., Icon. Pl. 1: t. 9. 1836; Arbutus empetrifolia Lam., Encycl. 1:155.1873; Andromeda humilis Banks et Sol., ex Hook. f., Fl. Antarct. 2:326. 1846; P. pumila (L. f.) Hook. var. empetrifolia (Lam.) Hook. f., Fl. Antarct.2:192. 1898.

Chaura, SHAL, SHAN ÁmAin

Subarbusto de unos 2-3 cm de altura, generalmente rastrero, cespitoso, con ramillas delgadas, pubescentes, carentes de setas. Hojas casi sésiles, laxamente imbricadas, coriáceas, glabras, pero finamente ciliadas bajo la lupa con una seta generalmente oscura a cada lado de la base de la lámina, de 2-3 (6) x 1,5 (3) mm, oblongo-elípticas, obtusas o algo agudas, margen entero, nervios poco marcados. Especie dioica. Flores unisexuales, solitarias, axilares, pediceladas, con 2-4 brácteas pequeñas y 2 bractéolas. Cáliz profundamente 5-partido, lóbulos de $2 \mathrm{~mm}$, aovado-triangulares y con el margen ciliado. Flores masculinas, cabizbajas, pedicelo de 6-10 (20) $\mathrm{mm}$; corola de $c a .3 \mathrm{~mm}$, algo acampanada; androceo con 10 estambres, casi iguales en tamaño, anteras fértiles. Flores femeninas, erguidas, pedicelos de 1-3,5 $\mathrm{mm}$, corola de 2,5 $\mathrm{mm}$, apenas campanulada; estambres estériles, gineceo con ovario fértil. Fruto una baya de color rosado o blanco, de 5-10 mm, esférica a elipsoide; sépalos verdes, no acrescentes, pedúnculo algo alargado durante la fructificación, de hasta $5 \mathrm{~mm}$ (Fig. 3a).

Distribución GeOgRÁfICA: Especie nativa de Chile y Argentina. La variedad típica crece entre las provincias de Valdivia (cordillera del lago Pirehueico) y la Región de Magallanes; en sitios abiertos y húmedos en la alta montaña y en la estepa patagónica.

ObServación: En ausencia de frutos se confunde con $G$. caespitosa.

Materiales estudiados:

Región de Los Lagos: Prov. Palena, Cerro Tigre cerca del Volcán Yates, 1400 m, 27-I-1944. Bernath 935 (SGO). Región de Aysén: Prov. Aysén, P.N. Laguna San Rafael, río Guala. 5-II-1959, F. Schlegel 2067 (CONC). Prov. General Carrera, volcán Hudson, 22-II-1993, R. Godoy, Hildebrand-Vogel \& A.Vogel, 55 (CONC). Prov. Capitán Prat, Villa O'Higgins, cuenca del Río Mosco, 20-III-2003, N. García 20 (CONC). Región de Magallanes: Prov. Última Esperanza, Puerto Edén, I-1954, J. Emperaire s/n. (CONC); Cerro Estancia Guido 700-900 m, 16-I-1952, A. Pfister \& M. Ricardi, (CONC); P. N. Torres del Paine, Cerro Diente, 21-XII-1985, M.T. Arroyo \& F. Squeo 85-0918. (CONC); Fiordo Falcon, costa este, 21-XII-1988, E. Pisano 6503 (CONC). Prov. Magallanes, Club de Esquí Punta Arenas, 500 m, 31-XII-1951, A. Pfister \& M. Ricardi s/n. (CONC); Isla Capitán Aracena, Bahía Transición, 12-XII-1972, E. Pisano 3326 (CONC); Fiordo Parry, P. N. Alberto M. de Agostini, caleta Alacaluf, costa, 05-II-1996, E. Pisano, J. M. Henríquez \& E. Domínguez 8624. Prov. de Tierra del Fuego, estancia Río Hondo, 12-II-1970, E. Pisano 2453 (CONC); Tierra del Fuego, Forestal Trillium, sector Vicuña, lote 12-A, 14-I-2004, E. Pisano \& J.M. Henríquez, 6943 (CONC). Prov. Antártica Chilena, Hermite island, Cape Horn, 1839-1843, ex Herb. Hooker (CONC); isla Navarino, Puerto Toro, 17-I-1972, E. Pisano 3468 (CONC). 

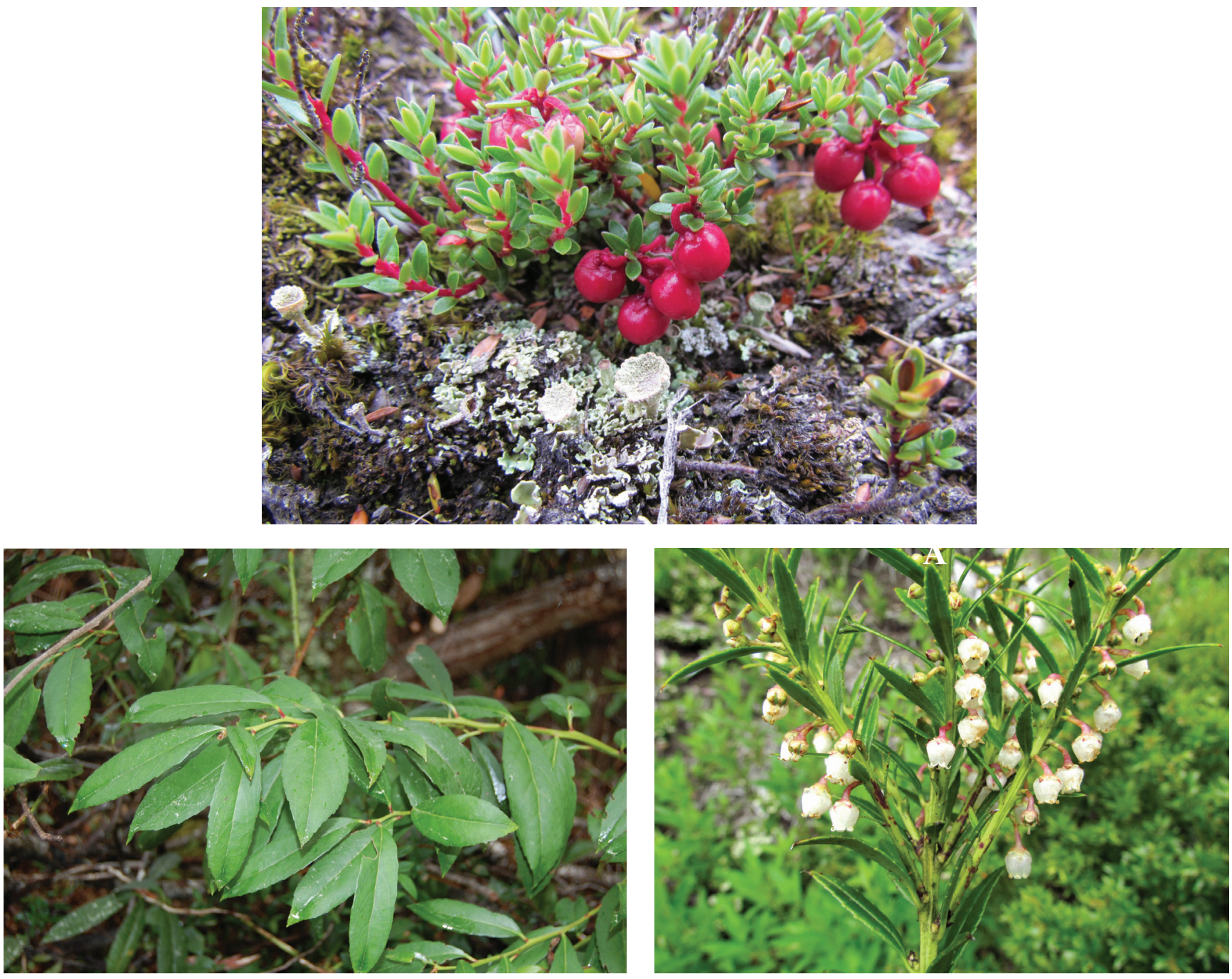

Figura 3. A. Gaultheria pumila (L.f.) D.J. Middleton, rama co.. frutos. Reserva Biológica de Huilo Huilo, cerro Piedra del Enıanto (Fotografía del autor); B. Gaultheria renjifoana Phil., rama con hojas. Colcura, provincia de Concepción (Fotografía de Diego Alarcón); C. Gaultheria tenuifolia (Phil.) Sleumer, rama con flores. Reserva Biológica de Huilo Huilo, cerro Piedra del Encanto (Fotografía del autor).

Figure 3. A. Gaultheria pumila (L.f.) D.J. Middleton, branch with fruits. Huilo Huilo Biological Reserve, mountains of Piedra del Encanto (Photo by the author); B. Gaultheria renjifoana Phil., branch with leafs. Colcura, provincia de Concepción (Photo: Diego Alarcón); C. Gaultheria tenuifolia (Phil.) Sleumer, flowering branch. Huilo Huilo Biological Reserve, mountains of Piedra del Encanto (Photo by the author).

Clave para las variedades

1. Hojas de 2-6 mm, tocándose por los bordes hasta casi imbricarse. Pedúnculo del fruto 4 veces más largo que las hojas. Plantas tendidas, frecuentemente menores que $5,0 \mathrm{~cm}$ de altura.

..G. pumila var. pumila

1. Hojas de 3-10 mm, casi no se topan por los bordes. Pedúnculo del fruto más corto o del largo de las hojas. Plantas con tallos algo erguidos, frecuentemente mayores que $5,0 \mathrm{~cm}$ de altura

G. pumila var. leucocarpa 
Gayana Bot. 70(1), 2013

9.a. Gaultheria pumila (L.f.) D.J. Middleton var. leucocarpa (DC.) D.J. Middleton

D.J. Middleton, Edinburgh. J. Bot. 47 (3): 298.1990.

Basiónimo: Pernettya leucocarpa DC., Prodr. 7:586.1839. "In Chili australis rupestribus frigidissimis inter muscos in latere australi montis ignivomi Antucencis ad 8500 ped.alt. Februario flor. Legit Poeppig".

Gaultheria leucocarpa Kunze ex DC., Prodr. 7:586.1839. Pernettya leucocarpa DC. var. gayana DC., Prodr.7: 586.1839; P. gayana (DC.) Decne., Voy. Pôle Sud II: tab. 23. 1852; P. empetrifolia (Lam.) Gaud. var. leucocarpa (DC.) Wedd., Chlor. And. 2:169. 1857; P. breviflora Phil., Linnaea 29:12. 1858; P. crassifolia Phil., Linnea 29: 10. 1858; P. trinervia Gand., Bull. Soc. Bot. France 60: 24. 1913; P. pumila (L.f.) Hook. var. crassifolia (Phil.) Sleumer, Lilloa 25: 539. 1952; G. pumila (L.f.) D.J. Middleton var. crassifolia (Phil.) D. J. Middleton, Edinb. J. Bot. 47 (3): 298.1990.

Las plantas difieren de la variedad típica por tener mayor altura, 4-6 (8) $\mathrm{cm}$; por las ramillas que son generalmente erguidas o procumbentes y menos densamente foliosas; por las hojas que no se imbrican, son algo mayores y alcanzan unos 3-4 (5) x 2,5 mm, algunos ejemplares del volcán Osorno (B. Sparre \& L. Constance 10176) presentan hojas casi lineares; y por el fruto de color blanco. Las plantas clasificadas como G. pumila var. crassifolia poseen los mismos caracteres y la misma área de distribución.

Se separa de las formas pequeñas de G. poeppigii por sus hojas consistentemente con margen entero y la casi ausencia de tallos aéreos leñosos.

Distribución GEOGRÁficA: variedad nativa de Chile y Argentina. En Chile crece desde la cordillera de la provincia de Los Andes (cuenca del río Colorado) hasta la cordillera del volcán Osorno. Crece en las vegas y en las laderas húmedas andinas.

Materiales estudiados: Región de Valparaíso: Prov. Aconcagua, Laguna Turquesa, cuenca del estero Castro y Río Blanco, 28-IV-2003, G. Mieres s/n. (CONC). Región Metropolitana: Prov. Santiago, La Disputada, 3600 m, 27I-1930, A. Garaventa 1534 (CONC); S. N. Yerba Loca, La Polvareda, 2630 m, 15-II-1999, M.T. Kalin-Arroyo \& Humaña 99-1808 (CONC). Prov. Cordillera, Río Claro, Cajón del Maipú, 2500 m, 23-I-1978, H. Niemeyer F. s/n. (CONC); M. N. El Morado, Cajón de Morales, Vegas del Ruhillas, 07-III-2002, S. Teillier \& C. Márquez 5173 (CONC). Región: de O’Higgins: Prov. Colchagua, quebrada El Maqui, Río Tinguiririca, 2100 m, I-1930 A. Pirion 133 ex Herb. Jaffuel. (CONC); Baños del Azufre, 18-II-1959, Barrientos 2082 (CONC). Región del Maule:
Prov. de Curicó, Laguna del Teno, 2500 m, 10-III-1967, C. Marticorena \& O. Matthei 915 (CONC). Prov. de Talca, paso Pehuenches, $2500 \mathrm{~m}, 13-\mathrm{II}-1963$. M. Ricardi, C. Marticorena \& O. Matthei, 934 (CONC). Región del Bío Bío: Prov. Nuble, Termas de Chillán valle de las Nieblas, 2000 m, 25-I-1936, A. Pfister s/n. (CONC); Termas de Chillán, subida al volcán, $2000 \mathrm{~m}, 06-\mathrm{I}-1949$, Pfister s/n. (CONC). Región de la Araucanía: Prov. de Malleco: paso Pino Hachado, 10-II-1960, M. Ricardi \& C. Marticorena 5091/1475 (CONC). Región de los Ríos: Prov. de Valdivia, Quechumalal, pampa El Olvido, 1000 m, 12-III-1958, F. Schlegel 1592 (CONC). Región de los Lagos: Prov. de Osorno, Antillanca, 1070 m, 24-III-1976, F. Schlegel 6819 (CONC). Prov. Llanquihue, Volcán Osorno, 1000 m, 16-III1954, B. Sparre \& L. Constance 10176 (CONC).

10. Gaultheria racemulosa (DC.) D.J. Middleton, D.J. Middleton, Edinburgh J. Bot. 47: 299. 1990.

Basiónimo: Pernettya racemulosa DC., Prodr. 7. 588. 1839. "In insula Juan Fernandez legit cl. Larrain qui ad Berterium misit".

Arbutus rigida Bert. ex Colla, Mem. Acc. Sci. Torino 38, 120. 1835; Pernettya rigida (Bert. ex Colla) DC., Prodr. VII. 587.1829; P. mucronata (L.f.) Gaudich. ex Spreng. var. mutica Hook. et Arn. J. Bot. 1:281.1834; P. bridgesii Phil., Anales. Univ. Chile, 13:167.1856.

Arbusto muy ramificado, de hasta $150 \mathrm{~cm}$ de altura, ramillas jóvenes rojizas, ramas adultas glabras, gruesas, rígidas, con la corteza rugosa. Hojas pecioladas $(1 \mathrm{~mm})$, glabras, coriáceas, densas, aovadas, de $(1,2) 1,5-2(2,5)$ x $0,6-1 \mathrm{~cm}$; margen aserrado y engrosado, con 6-8 (10) dientes; el envés con las nervaduras prominentes. Especie ginodioica. Flores unisexuales o hermafroditas, solitarias, axilares, terminales, pedúnculos y pedicelos (1-1,5 cm de largo) con 4-5 brácteas. Cáliz con lóbulos aovado-acuminados, glabros, de $2 \mathrm{~mm}$; corola blanca, urceolada de 4-5 mm de largo, con lóbulos de $1,5 \mathrm{~mm}$; con estambres fértiles en las flores masculinas y en las hermafroditas, anteras bi-apendiculadas; flores femeninas y hermafroditas con ovario globoso 1,5-2 $\mathrm{mm}$ de largo, estigma grueso. Fruto, una baya roja, de hasta $10 \mathrm{~mm}$ de diámetro, sépalos verdes, no engrosados en la madurez del fruto.

DisTRIBUCIÓN GEOGRÁFICA: Especie endémica del archipiélago de Juan Fernández, dominante en el matorral montano que crece por encima del piso del bosque. En la isla Robinson Crusoe se encuentra desde $150 \mathrm{~m}$ de altitud hasta las altas cumbres; en la isla Alejandro Selkirk se encuentra desde los $500 \mathrm{~m}$ hacia arriba.

Observaciones: Fue clasificada como especie vulnerable por el Ministerio del Medio Ambiente (D.S. No 33-2012). 
Materiales estudiados:

Región de Valparaíso: Prov. de Valparaíso, Juan Fernández, 02-III-1830, C. Bertero s/n. (SGO-Foto del tipo de Arbutus rigida Bert. ex Colla); Juan Fernández. T. Bridges (SGO, tipo de $P$. bridgesii); Isla Más a Tierra, portezuelo de Villagra, 200 m, 14-II-1935, K. Behn (CONC); isla Más a Tierra, El Camote, 600 m, 01-II-1980, C. Marticorena \& Ugarte 9091 (CONC); Isla Más a Tierra, Mirador de Selkirk, 575 m, 28-I1980, T. Stuessy \& Sanders 5018 (CONC); Isla Más Afuera, from mouth of quebrada Las Vacas to Las Torres, 690, 02-II1980, T. Stuessy, R. Rodríguez, Sanders \& Arriagada 5072 (CONC); Isla Más Afuera, quebrada Helecho Bonito, 790 m, 24-I-1984, T. Stuessy, Crawford, E. Ruiz \& L. Landeros 6367 (CONC).

\section{Gaultheria renjifoana Phil.}

R. A. Philippi, Anales Univ. Chile. 65: 60. 1884. "Reperi Martio 1884 pariter in monte de Villagran dicto;...”

Arbusto de hasta 2,5 m; ramas flexibles. Hojas pecioladas, glabras, coriáceas, a veces de un tono algo pardo claro a rojizo, otras verde claro a pardo claro; lámina de 6,5$11 \times 2-4,5 \mathrm{~cm}$, aovado-lanceoladas hasta elípticas, borde ligeramente aserrado, con unos 17-28 dientes pequeños; ápice agudo. Flores hermafroditas, dispuestas en cimas terminales con 10-20 flores, pedúnculos y pedicelos con brácteas y bractéolas triangulares, agudas en el ápice. Cáliz con 5 lóbulos aovado-lanceolados; corola blanca, urceolada, 4-5,5 mm, con 5-lóbulos; estambres 10, con las anteras largamente bi-aristadas. Fruto una cápsula, en su madurez rodeada por los sépalos rosados y carnosos que la abrazan casi por completo (Fig. 3b).

Distribución geográficA: Especie endémica de Chile. Crece solamente en la costa de la Región del Bío-Bío, entre las localidades de Colcura y Chivilingo.

OBSERVACIONES: Especie muy escasa y muy amenazada por la destrucción de antigua data del bosque nativo en su reducido ámbito de distribución. Prácticamente todas las colecciones conocidas proceden de la misma área y de unos pocos individuos. Desafortunadamente ha sido incluida erróneamente en la sinonimia de Gaultheria insana (Sleumer 1985; Middleton \& Wilcock 1990; Zuloaga et al. 2008) que es una especie completamente diferente (Kausel 1949, Muñoz-Schick 1987), con la que comparte el hábitat, lo que ha dificultado las acciones de conservación.

Materiales estudiados: Región del Bío Bío: Prov. de Arauco, Cerro de Villagrán, III-1884, R.A. Philippi (SGO, tipo de $G$. renjifoana Phil.); Laraquete, orillas del río Laraquete, 10-III-1950, M. Ricardi \& Acuña (CONC); Laraquete, orillas del Río, 6 km del pueblo, 13-XII-1950, A. Pfister \& M. Ricardi (CONC); Chivilingo, Puente Mellizos, orillas del río, 5-I-1966. M. Ricardi \& C. Marticorena 5407 (CONC); Quebrada Honda, Puente Mellizos, 21-IV-1976, C. Marticorena, M. Quezada \& R. Rodríguez 1066 (CONC); Central hidroeléctrica Chivilingo, sector Bocatoma, Puente Nuevo ex Puente Mellizos, 200 m, 23-II-1987, M. MuñozSchick, 2150 (SGO).

\section{Gaultheria tenuifolia (Phil.) Sleumer}

Sleumer, Notizbl. Bot. Gart. Berlin-Dahlem 13: 207. 1936.

Basiónimo: Pernettya tenuifolia Phil., Linnaea 29:10. 1858. "In provincia Valdivia legitur."

Pernettya elegans Phil., Linnaea 33:172.1864-5; P. reticulata Phil., Anales Univ. Chile. 43:507.1873; Gaultheria salicifolia Phil., Anales Univ. Chile 90:192.1895; P. promaucana Phil., Anales Univ. Chile 90:195.1895; G. elegans (Phil.) Reiche, Anales Univ. Chile 117: 498.1905; G. tenuifolia (Phil.) Sleumer var. elegans (Phil.) Kausel, Revista Univ. (Santiago) 34: 174.1949; G. tenuifolia (Phil.) Sleumer var. promaucana (Phil.) Kausel, Revista Univ. (Santiago) 34: 175. 1949.

Arbusto de hasta 2,5 m altura; ramillas angulosas, comprimidas y glabras. Hojas pecioladas $(1,5 \mathrm{~mm})$, coriáceas, glabras y lustrosas, algunas poblaciones con las hojas con olor penetrante a salicilato de metilo; lámina de (20) 23-35 (50) x 3-9 (11) mm, linear-elíptica hasta oblongaelíptica; débilmente falcada y terminada en un mucrón agudo; borde con 6-7 (8) dientes pequeños y redondeados, más o menos profundos a ambos lados, a veces, casi entero; nervio central prominente en el envés. Especie dioica. Flores unisexuales, solitarias, axilares y cabizbajas, pedicelo de unos $10 \mathrm{~mm}$, con varias brácteas pequeñas y 2-4 bractéolas en la base. Cáliz profundamente 5-partido, lóbulos de $+1,8$ $\mathrm{mm}$, triangulares y agudos. Corola de $+4 \mathrm{~mm}$, urceoladocilíndrica. Flores masculinas con 10 estambres, 5 apenas más largos, anteras fértiles y ovario estéril. Las femeninas, también con 10 estambres, casi del mismo tamaño con anteras estériles; gineceo con ovario fértil de 1,2-1,5 mm. Fruto, una cápsula de 4-5 $\mathrm{mm}$ diámetro, subcoriácea, rodeada casi enteramente por los lóbulos del cáliz; éstos carnosos y de color castaño-rojizo en su madurez (Fig. 3c).

DistribuCión GEOGRÁfiCA: Especie nativa de Chile y Argentina. Crece entre la provincia de Talca (Laguna del Maule) y la de La Unión (en la Cordillera Pelada). Se encuentra en los márgenes de los bosques de Nothofagus obliqua y $N$. dombeyi.

OBSERVACIONES: La presencia de flores más pequeñas, rosadas y solitarias; y el color rosado del fruto son caracteres seguros para identificarla. En ausencia de frutos algunos individuos 
con hojas lanceoladas y más cortas se pueden confundir con G. phyllireifolia, con la que posiblemente forma híbridos. Los ejemplares con hojas lanceoladas se pueden confundir con los de G. mucronata var. angustifolia.

Al parecer existen dos grupos de poblaciones peculiares; las costeras en el límite norte de la distribución que presentan hojas más anchas y obovadas ("var. promaucana"); las interiores y hacia el límite sur con hojas estrechas y elípticas ("var. elegans").

Materiales estudiados: Región del Maule: Prov. de Talca, Constitución, Azocart (SGO: tipo de P. promaucana Phil.); Quebrada Paso de Mora, 16-V-1985, A. Troncoso \& J. San Martín s/n. (SGO). Prov. de Cauquenes, Pelluhue, 190 m. C. Aedo 7170, 14-XII-2001 (CONC); R.N. Los Ruiles, La Tupía, 190 m, 26-I-2003, Gardner, Hechenleitner, Martínez \& Thomas 160 (CONC). Prov. de Linares, R. N. Bellotos del Melado, 1350 m, 04-I-2000, Humaña, Mac Pherson \& Valdivia 2002-9 (CONC). Región del Bío Bío: Prov. de Ñuble, Termas de Chillán, II-1933, Jaffuel s/n. (CONC). Las Trancas, camino a las Termas de Chillán, 03-III-1979, R. Rodríguez 1175 (CONC). Región de la Araucanía: Prov. de Malleco, Nahuelbuta. Volckmann (SGO, tipo de P. reticulata Phil.); P.N. Nahuelbuta, Pichinahuel, $1300 \mathrm{~m}$, 09-I-1968, M. Ricardi, C. Marticorena \& O. Matthei 1964 (CONC); Termas de Tolhuaca, 1050 m, 25-I-1979, J. \& A. Solomon 4487 (CONC). Prov. de Cautín, volcán Llaima, 2200 m, 20-II-1988, Gardner \& Knees 4241(CONC). Región de los Ríos: Prov. de Valdivia, in dumetis Valdivia, enero 1835, C. Gay (SGO, tipo de P. tenuifolia Phil.); bosquete del Lago Ranco, Pearce (SGO, tipo de G. elegans Phil.). Prov. de La Unión, cordillera Pelada, $60 \mathrm{~km}$ W de La Unión, 900-1000 m, 19-IV-1982, Landrum 4514 (SGO); M. N. Alerce Costero, altos de Mirador, 950 m, 7-II-1988, Gardner \& Knees 4114 (CONC).

\section{INCERTAE SEDIS}

Existen ejemplares-tipo que carecen de frutos que han sido atribuidos por diferentes autores a diferentes especies, que no hemos podido adscribir con seguridad a ninguna de las presentadas en este tratamiento.

Pernettya linifolia Phil., Linnaea 33:172. 1864-65.

Pernettya mucronata (L. f.) Gaudich. ex Spreng. var. linifolia (Phil.) Reiche, Anales Univ. Chile 117: 491.1906; Pernettya leucocarpa DC. var. linearis Reiche, pro parte, Anales Univ. Chile 117: 494.1906; Pernettya prostrata (Cav.) DC. var. linifolia (Phil.) Sleumer, Notizbl. Bot. Gart. Berlin-Dahlem 13: 211.1936; Pernettya myrtilloides Zucc. ex Steud. var. linifolia (Phil.) Kausel, Revista Univ. (Santiago) 34: 164.1949; Pernettya poeppigii (DC.) Klotzsch var. linifolia (Phil.) Sleumer, Lilloa 25: 550.1952; Gaultheria poeppigii DC. var. linifolia (Phil.) D.J.
Middleton, Edinburgh J. Bot. 47 (3):298.1990.

Typus: Inter Corral y Río Bueno. Pearce (SGO).

El material base consiste en dos ejemplares que carecen de frutos, que presentan hojas extremadamente angostas, agudas o un poco mucronadas. Uno de ellos constituye el tipo de $G$. linifolia, que ha sido transferido tanto a $G$. mucronata (Reiche 1905) como a G. poeppigii (Kausel 1949; Sleumer 1952).

La localidad del tipo es "inter Corral y Río Bueno", quizás algún lugar de la Cordillera Pelada (Región de Los Ríos). Un segundo ejemplar, similar, se encontró en el herbario de F. Philippi (SGO) recolectado en el Río Huaycoya (¿Hueicolla?), entre las localidades de Corral y Lamihuapi. El ejemplar de la fotografía 15, similar a la exsiccata referida, fue recolectado en la R.N. Valdivia por R. Charlín y colaboradores. Ante la ausencia de frutos y la escasez de material hemos preferido no asignarlo ni a G. mucronata ni a G. poeppigii.

Pernettya palenae Phil. Anal. Univ. Chile 90:195.1895. Typus: Río Palena, 01-02-1887, Delfin (SGO).

Reiche (1905) la consideró como una buena especie. Kausel (1949) la incluyó en la sinonimia de G. phyllireifolia; aunque en el apéndice de su trabajo sugiere que podría ser tratada como una variedad de G. poeppigii (P. myrtilloides). $\mathrm{El}$ aspecto de la planta se asemeja más a el de G. poeppigii, pero al carecer de frutos cualquier asignación es insegura. El ejemplar SGO 53707 está anotado por Philippi como $P$. myrtifolia; y tiene una etiqueta de corrección que dice P. palenae Phil. P. myrtifolia no figura en Muñoz Pizarro (1960).

Pernettya quadrifida Phil., Linnaea 29: 11. 1858.

Typus: Cerro 12 de febrero, entre los lagos Todos los Santos y Nahuel Huapi, Fonk (SGO).

Reiche (1905) la incluye entre las "especies problemáticas". Kausel (1949) por las características de las flores la considera como sinónima de G. caespitosa. A nuestro juicio el carácter leñoso de los tallos coincide mejor con alguna forma enana de G. poeppigii. El ejemplar carece de frutos.

\section{AGRADECIMIENTOS}

Los autores agradecen a los curadores y al personal de los herbarios SGO y CONC por su amable disposición para consultar aquellos materiales indispensables para esta revisión. A Diego Alarcón agradecemos sus sugerencias y la fotografía de Gaultheria renjifoana; a Patricio Novoa por la foto de G. nubigena. Al Sr. K. Gandhi por su aclaración sobre la ortografía de G. renjifoana. Al Dr. Roberto Rodríguez y 
a Alicia Marticorena, les agradecemos sus sugerencias para mejorar el manuscrito.

\section{BIBLIOGRAFÍA}

Brako, L. \& J. L. Zarucchi. 1993. Catalogue of the Flowering Plants and Gymnosperms of Peru. Systematic Botany Monograph 45. Missouri Botanical Garden. 1286 pp.

Bush, C., \& K.A. Kron. 2008. Phylogeny of Gaultherieae (Ericaceae) based on DNA sequence data from matK, $\mathrm{ndhF}$ and ITS. P. 93, in Botany 2008. Botany without Borders. [Botanical Society of America, Abstracts.]

Bush, C., L. Lu, P.W. Fritsch \& K.A. Kron. 2006. The phylogeny, morphology and biogeography of the wintergreen group (Gaultherieae; Vaccinoideae; Ericaceae; Ericales). Pp. 209210, In: Botany 2006 - Looking to the Future - Conserving the Past. [Abstracts: Botanical Society of America]

Bush, C.M., L. Lu, P.W. Fritsch, D.-Z. Li \& K.A. Kron. 2009. Phylogeny of Gaultherieae (Ericaceae: Vaccinoideae) based on DNA sequence data from matK, ndhF, and nrITS. International Journal of Plant Science 170: 355-364.

Domínguez, E. 2010. Flora de interés etnobotánico usada por los pueblos originarios: Aónikenk, Selk'nam, Kawésqar, Yagan y Haush en la Patagonia Austral. Dominguezia 26(2): 19-29.

Hechenleitner, P., M.F. Gardner, P.I. Thomas, C. Echeverría, P. Brownless \& C. Martínez. 2005. Plantas amenazadas del centro-sur de Chile. Distribución, Conservación y Propagación. Primera edición. Universidad Austral de Chile y Real Jardín Botánico de Edinburgo.188 pp.

Hermann, P.M. \& V. N. CAmbi. 1992. Nuevos datos sobre la sexualidad de Gaultheria caespitosa Poepp. et Endl. (Ericaceae). Parodiana 7(1-2): 83-90.

Hermann, P.M. \& V. N. CAmBI. 2006. Gaultheria nubigena (Ericaceae), una especie rara en la Argentina. Bol. Soc. Argent. Bot. 41(3-4). 317-322. Disponible en: $<$ http://www. scielo.org.ar/scielo.php?script=sci_arttext\&pid=S1851$23722006000200013 \& \operatorname{lng}=\mathrm{es} \& \mathrm{nrm}=\mathrm{iso}>$. ISSN 1851 2372.

Kausel, E. 1949. Comentario sobre las ericáceas y epacridáceas chilenas. Revista Universitaria (Santiago). 34(I):155-178.

Luebert, F. \& P. Pliscoff. 2006. Sinopsis bioclimática y vegetacional de Chile. Editorial Universitaria. Santiago de Chile. 316 pp.

MabBerLey, D.J. 1987. The plant book. A portable dictionary of the higher plants. Cambridge University Press. Cambridge. UK. 706 pp.

Middleton, D.J. \& C. C. Wilcock. 1990. A critical examination of the status of Pernettya as a genus distinct from Gaultheria.
Edinburgh Journal of Botany 47(3): 291-301.

Mösbach, E.W. DE. 1992. Botánica indígena de Chile. C. Aldunate y C. Villagrán, editores. Editorial Andrés Bello, Santiago de Chile. 140 pp.

Muñoz Pizarro, C. 1960. Las especies de plantas descritas por R. A. Philippi en el siglo XIX. Ediciones de la Universidad de Chile-Santiago de Chile. 189 pp.

Muñoz Pizarro, C. \& E. Pisano. 1947. Estudio de la vegetación y flora de los parques nacionales de Fray Jorge y Talinay. Agricultura Técnica 2: 71-190.

MuÑoz-Schick, M. 1987. Fundamentos para la revalidación de Gaultheria renjifoana Phil. (Ericaceae). Gayana Bot. 44(14): 33-37.

Museo Nacional de Historia Natural de París (sitio web oficial): (http://www.mnhn.fr/museum/foffice/science/science/ sommaire.xsp).

PARdo, O. \& J. L. PizarRo. 2005. Especies botánicas consumidas por los chilenos prehispánicos. Colección Chile precolombino. Editorial Mare Nostrum. Santiago de Chile. 228 pp.

Reiche, K. 1905. Estudios críticos sobre la flora de Chile. Ericaceae. Anales Univ. Chile 117: 487-500.

Riedemann, P. \& G. Aldunate. 2003. Flora nativa de valor ornamental Chile, zona sur. Identificación y propagación. Editorial Andrés Bello. 517 pp.

Sleumer, H. 1935. Revision der Gattung Pernettya Gaud. Notizblatt des Botanischen Gartens und Museums zu Berlin-Dahlem 12: 626-655.

Sleumer, H. 1985. Taxonomy of the genus Pernettya Gaud. (Ericaceae). Botanische Jahrbücher für Systematik, Pflanzengeschichte und Pflanzengeographie. Leipzig 105 (4): 449-480.

Sleumer, H. \& P. Hermann. 1999. Flora Patagonica. Ericaceae. Tomo VIII. Parte VI. 1-15.

Schmithüsen, J. 1956. Die räumliche Ordnung der chilenischen Vegetation. Bonner Geographische Abhandiungen 17: $1-86$.

Squeo, F.A., G. Arancio \& J. R. Gutiérrez. 2001. Libro rojo de la flora nativa y de los sitios prioritarios para su conservación: Región de Coquimbo. Ediciones Universidad de La Serena. $372 \mathrm{pp}$.

Stevens, P.F. 1971. A classification of the Ericaeae: subfamilies and tribe. Botanical Journal of the Linnean Society 64: $1-53$.

Stevens, P.F. (2001 onwards). Angiosperm Phylogeny Website. Version 9, June 2008. URL: http://www.mobot.org/ MOBOT/research/APweb/.

Zuloaga, A., O. Morrone \& M.J. Belgrano (eds.). 2008. Catálogo de la flora vascular del cono sur. Base de datos asociada en INTERNET: http://www.darwin.edu.ar/Proyectos/ FloraArgentina/FA.asp (Consultada 20-01-2012). 


\section{ÍNDICE DE NOMBRES CIENTÍFICOS}

Andromeda humilis Banks et Sol. 146

Arbutus empetrifolia Lam. 146

Arbutus furiens Hook. \& Arn. 141

Arbutus mucronata L.f. 142

Arbutus phillyreifolia Pers. 144

Arbutus pumila L.f. 146

Arbutus punctata Hook. \& Arn. 141

Arbutus rigida Banks 148

Arbutus rigida Bert. ex Colla 142

Arbutus serpyllifolia Lam. 140

Arbutus vernalis Poepp. \& Endl. 141

Gaultheria angustifolia (Lind1.) Teillier 138, 139, 140, 142

Gaultheria antarctica Hook. f. 139, 140, 141

Gaultheria caespitosa Poepp. et Endl. 139, 140, 146, 150

Gaultheria elegans (Phil.) Reiche 149

Gaultheria floribunda Phil. 145

Gaultheria florida Phil. 144, 145

Gaultheria furiens (Hook. \& Arn.) 141

Gaultheria insana (Molina) D.J.Middleton 139, 141, 142, 149

Gaultheria lanceolata Phil. 144

Gaultheria leucocarpa Kunze ex DC. 148

Gaultheria microphylla Hook. f. 140

Gaultheria minima (Phil.) Sandwith 140

Gaultheria mucronata (L.f.) Hook. et Arn. 139, 142, 143, 145, 150

Gaultheria mucronata (L.f.) Hook. et Arn. var. angustifolia (Lindl.) D.J. Middleton 138, 150

Gaultheria mucronata (L.f.) Hook. et Arn. var. microphylla (Hombr.) D.J. Middleton 142

Gaultheria mucronata Phil. 144

Gaultheria myrtilloides Hook. \& Arn. 144

Gaultheria myrtilloides Hook. \& Arn. var. minor Hook. \& Arn. 142

Gaultheria myrtilloides Hook. \& Arn. var. racemosa (Phil.) Reiche 144

Gaultheria myrtilloides Poepp. \& Endl. 145

Gaultheria nubigena (Phil.) Burtt et Sleumer 143, 144

Gaultheria phillyreifolia (Pers.) Sleumer 142, 143, 144, 145, 150

Gaultheria phillyreifolia (Pers.) Sleumer var. florida (Phil.) Kausel 144, 145

Gaultheria poeppigii DC. 139, 142, 143, 145, 148, 150

Gaultheria poeppigii DC. var. linifolia (Phil.) D.J. Middleton 150

Gaultheria poeppigii DC. var. nana (Sleumer) D.J. Middleton 145

Gaultheria pumila (L.f.) D.J. Middleton 140, 141, 145, 146, 147

Gaultheria pumila (L.f.) D.J. Middleton var. crassifolia (Phil.) D.J. Middleton 148

Gaultheria pumila (L.f.) D.J. Middleton var. leucocarpa (DC.) D.J. Middleton 141, 146, 148

Gaultheria punctata (Hook. \& Arn.) Hook. \& Arn 141

Gaultheria racemulosa (DC.) D.J. Middleton, 148

Gaultheria renjifoana Phil. 141, 146, 149

Gaultheria salicifolia Phil. 149

Gaultheria serpyllifolia (Lam.) Skottsb. 140

Gaultheria tenuifolia (Phil.) Sleumer 139, 146, 149

Gaultheria tenuifolia (Phil.) Sleumer var. elegans (Phil.) Kausel 149

Gaultheria tenuifolia (Phil.) Sleumer var. promaucana (Phil.) Kausel 149

Gaultheria vernalis (Poepp. \& Endl.) Kunze 141

Hippomanica insana Molina 141

Pernettya angustifolia Lindl. 138, 140

Pernettya breviflora Phil. 148

Pernettya bridgesii Phil. 148

Pernettya buxifolia Phil. 145

Pernettya crassifolia Phil. 148

Pernettya elegans Phil. 149 
Pernettya empetrifolia (Lam.) Gaudich. 146

Pernettya empetrifolia (Lam.) Gaud. var. leucocarpa (DC.) Wedd. 148

Pernettya furiens (Hook. \& Arn.) Klotzsch 141

Pernettya gayana (DC.) Decne. 148

Pernettya hookeri Nied. 140

Pernettya insana (Molina) Gunckel 141

Pernettya leucocarpa DC. 148

Pernettya leucocarpa DC. var. buxifolia (Phil.) Reiche 145

Pernettya leucocarpa DC. var. gayana DC. 148

Pernettya leucocarpa DC. var. linearis Reiche 138, 140, 150

Pernettya linifolia Phil. 150

Pernettya litoralis Phil. 142

Pernettya melanocarpa Phil. 141

Pernettya minima Phil. 140

Pernettya mucronata (L.f.) Gaudich. ex Spreng. 142

Pernettya mucronata (L.f.) Gaudich. ex Spreng. var. angustifolia (Lindl.) Reiche 138

Pernettya mucronata (L.f.) Gaudich. ex Spreng. var. linifolia (Phil.) Reiche 150

Pernettya mucronata (L.f.) Gaudich. ex Spreng. var. microphylla (Phil.) Reiche 142

Pernettya mucronata (L.f.) Gaudich. ex Spreng. var. microphylla Hombr. 142

Pernettya mucronata (L.f.) Gaudich. ex Spreng. var. mutica Hook. et Arn. 148

Pernettya mucronata (L.f.) Gaudich. ex Spreng. var. parvifolia (Phil.) Skottsb. 142

Pernettya mucronata (L.f.) Gaudich. ex Spreng. var. rupicola (Phil.) Reiche 142

Pernettya myrtilloides Zucc. ex Steud. var. linifolia (Phil.) Kausel 150

Pernettya myrtilloides Zucc. ex Steud. var. nana (Sleumer) Sleumer 145

Pernettya myrtilloides Zucc. ex Steud. 145,150

Pernettya nubigena Phil. 144

Pernettya oblongifolia Hombr. \& Jacquinot ex Decne. 142

Pernettya ovalifolia Hombr. \& Jacquinot ex Decne. 142

Pernettya palenae Phil. 150

Pernettya parvifolia Phil. 142

Pernettya patagonica Speg. 145

Pernettya philippiana Speg. 145

Pernettya philippii Gand. 144

Pernettya phillyreifolia (Pers.) DC. 144

Pernettya phillyreifolia (Pers.) DC. var. araucana Kuntze 145

Pernettya poeppigii (DC.) Klotsch var. nana Sleumer 145

Pernettya poeppigii (DC.) Klotzsch 145

Pernettya poeppigii (DC.) Klotzsch var. linifolia (Phil.) Sleumer 150

Pernettya promaucana Phil. 149

Pernettya prostrata (Cav.) DC. var. linifolia (Phil.) Sleumer 150

Pernettya pumila (L. f.) Hook. 146

Pernettya pumila (L. f.) Hook. var. empetrifolia (Lam.) Hook. f. 146

Pernettya pumila (L.f.) Hook. var. crassifolia (Phil.) Sleumer 148

Pernettya punctata (Hook. \& Arn.) Klotzsch 141

Pernettya quadrifida Phil. 150

Pernettya racemulosa DC. 148

Pernettya reticulata Phil. 149

Pernettya rigida (Bert. ex Colla) DC. 148

Pernettya rupicola Phil. 142

Pernettya serpyllifolia (Lam.) DC. 140

Pernettya tenuifolia Phil. 149

Pernettya trinervia Gand. 148

Pernettya vernalis (Poepp. \& Endl.) Phil. 141

Recibido: 14.09 .11

Aceptado: 08.03.13 